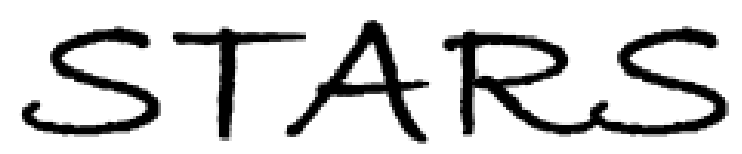

University of Central Florida

STARS

\title{
Managing an Epidemic: Zika Interventions and Community Responses in Belize
}

Deven Gray

University of Central Florida

\section{Part of the Anthropology Commons}

Find similar works at: https://stars.library.ucf.edu/etd

University of Central Florida Libraries http://library.ucf.edu

This Masters Thesis (Open Access) is brought to you for free and open access by STARS. It has been accepted for inclusion in Electronic Theses and Dissertations by an authorized administrator of STARS. For more information, please contact STARS@ucf.edu.

\section{STARS Citation}

Gray, Deven, "Managing an Epidemic: Zika Interventions and Community Responses in Belize" (2018). Electronic Theses and Dissertations. 6216.

https://stars.library.ucf.edu/etd/6216

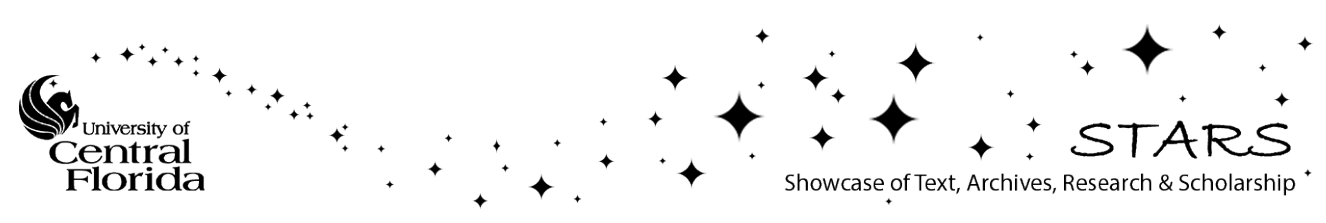




\title{
MANAGING AN EPIDEMIC: ZIKA INTERVENTIONS AND COMMUNITY RESPONSES IN BELIZE
}

by

\author{
DEVEN G. GRAY \\ B.A. University of Central Florida, 2016 \\ A thesis submitted in partial fulfillment of the requirements \\ for the degree of Master of Arts \\ in the Department of Anthropology \\ in the College of Sciences \\ at the University of Central Florida \\ Orlando, Florida
}

Spring Term

2018

Major Professor: Joanna Mishtal 
C 2018 Deven Gray 


\begin{abstract}
Implementing effective health interventions in recent epidemics has been difficult due to the potentially global nature of their spread and sociocultural dynamics, raising questions concerning how to develop culturally-appropriate preventive measures, and how these health threats are understood locally. In Belize, health policy makers have only been marginally effective in managing infections and mosquito vectors, and Zika has been declared endemic in multiple regions of the country, particularly on the island of Caye Caulker. With one locally confirmed case of microcephaly on this small island already, this disease has the potential to severely impact the health and wellness of pregnant women and future generations. Based on ethnographic and Geographic Information Systems research conducted primarily in 2017, I examine how perspectives of Zika-related health risk are shaped, and how state interventions to manage Zika are understood. I argue that despite its declared endemic status, Zika is not perceived as a true health concern for community members due to numerous neoliberal structural challenges. Moreover, the state's restrictive form of reproductive governance which limits family planning services is forcing individuals to weigh conflicting conceptions of health consequences. This also contributes to an ambiguous healthcare environment for health practitioners, giving them an unclear picture of the scope of Zika as a public health concern and limiting their ability to treat patients. This thesis also considers how critical medical anthropology and feminist analytical approaches are useful in exploring these questions and contributing to understandings of the health impacts of Zika.
\end{abstract}




\section{ACKNOWLEDGMENTS}

I would like to express my gratitude toward the Caye Caulker community and research participants who agreed to take part in this study. I also thank my Master's Comitttee and the Committee Chair for their support and valuable feedback on my Research Proposal which has shaped the direction of this project. This work was funded by the National Geographic Society under grant HJ-061ER-17. 


\section{TABLE OF CONTENTS}

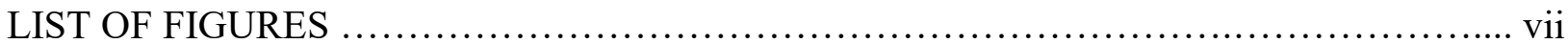

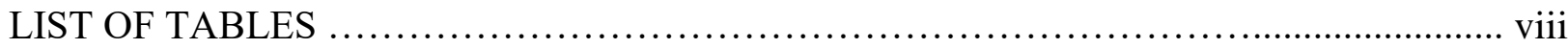

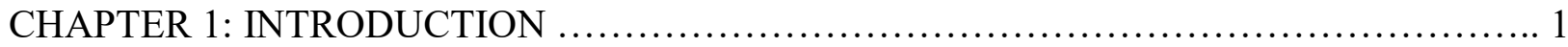

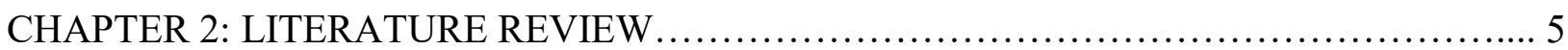

Monitoring Pregnancy, Governing Reproduction ....................................................... 5

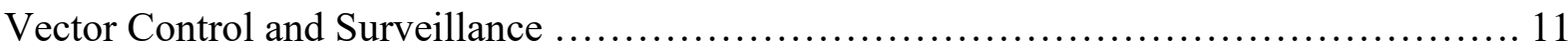

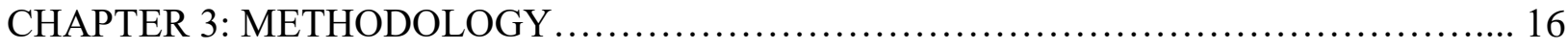

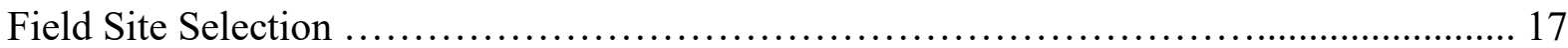

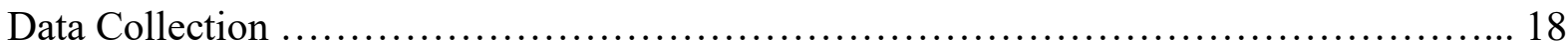

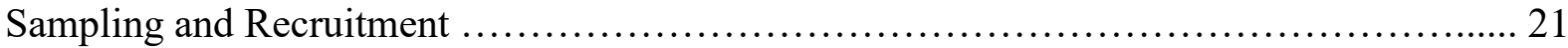

Data Management and Analysis ...................................................... 29

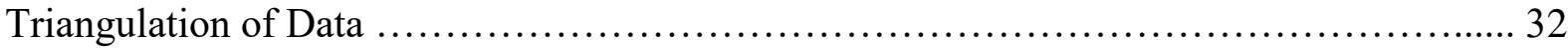

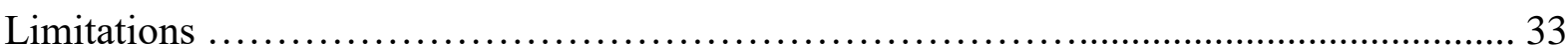

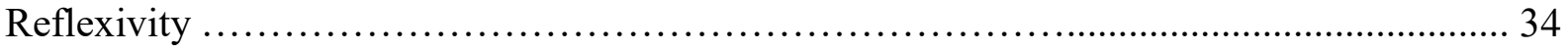

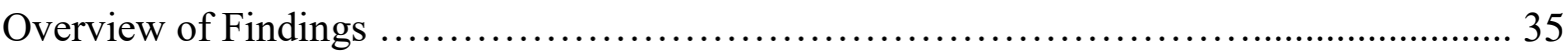

CHAPTER 4: “I THINK ZIKA ONLY REALLY AFFECTS PREGNANT WOMENT”:

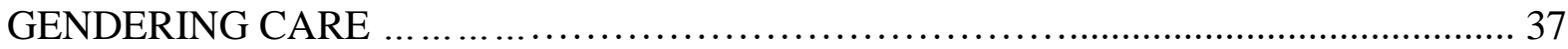

CHAPTER 5: “OFFICIAL” AND “UNOFFICIAL” ZIKA: AMBIGUITIES IN THE

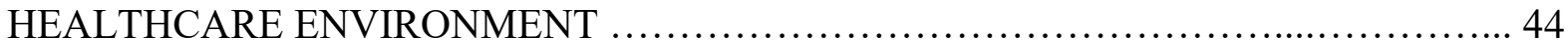

CHAPTER 6: "YOU KNOW THIS ZIKA STUFF IS JUST A MYTH, RIGHT?”: COMPETING

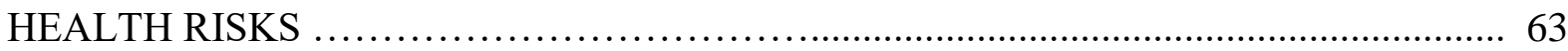


CHAPTER 7: CONCLUSIONS

APPENDIX A: IRB APPROVAL LETTER: ........................................... 83

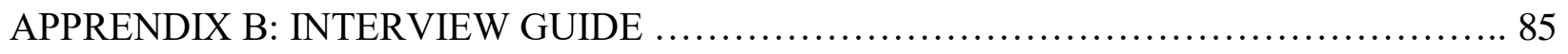

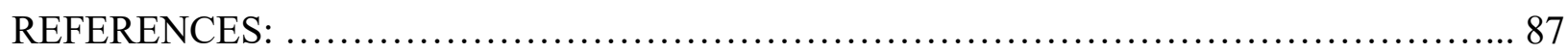




\section{LIST OF FIGURES}

Figure 1: "Noh Get Bite" pamphlet................................................... 45

Figure 2: One of the many litter hotspots in residential areas. Photo: Deven Gray............... 47

Figure 3: A loaded cart used by private garbage collectors. Residents must pay for this service.

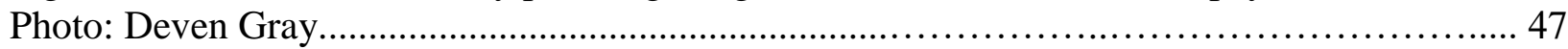

Figure 4: One of the government owned trash cans in the commercial district. Notice the small openings at the top to insert trash and to prevent household garbage bags from being deposited.

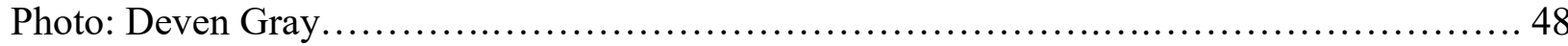

Figure 5: Kernel Density analysis of the distribution of businesses in Caye Caulker. Blue is least clustered while red indicates a high degree of clustering....................................... 51

Figure 6: Overview of the distribution of trash bins, litter clustering, and standing water within

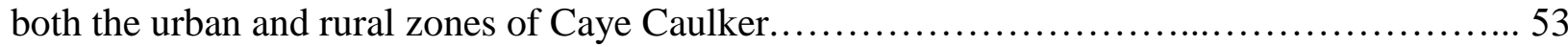

Figure 7: Distribution of trash bins, litter clustering, and standing water specific to the rural zone

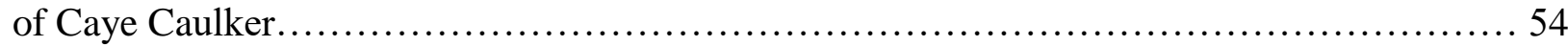

Figure 8: Distribution of trash bins, litter clustering, and standing water specific to the urban

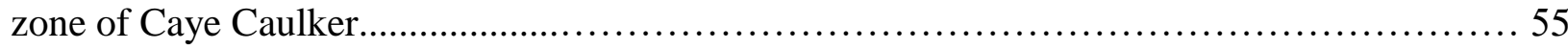

Figure 9: Business density compared to waste management in Caye Caulker...................... 59

Figure 10: Woman covering her face with a cloth to not breath in fumigation chemicals. Photo:

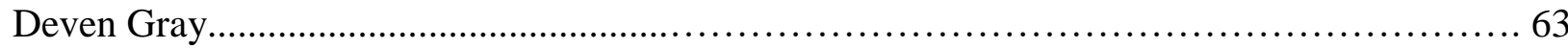

Figure 11: Vector control vehicle parked to fumigate section of rural zone. Photo: Deven Gray. 65

Figure 12: Vector control about to begin fumigation in urban zone. A man in the background can be seen covering his face. Photo: Deven Gray............................................... 65

Figure 13: Risk factor analysis of litter and standing water for mosquito breeding with data

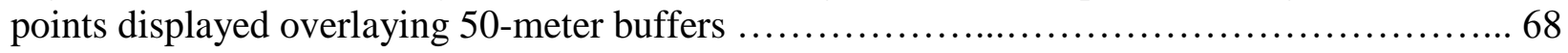

Figure 14: Risk factor analysis of litter and standing water for mosquito breeding with data points not shown. Notice overlap of standing water and litter buffer zones..................... 69

Figure 15: Two examples of commonly utilized paths for walking from the rural neighborhood of Bahia and the nearest grocery store. There are limited options for streets which I have indicated by breaking up of the red path. 


\section{LIST OF TABLES}

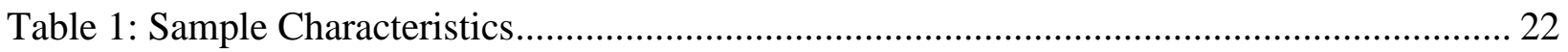




\section{CHAPTER 1: INTRODUCTION}

Implementing effective health interventions in recent epidemics (e.g. HIV/AIDS, SARS, Ebola) has been difficult due to the global nature of their spread and cultural dynamics, raising questions concerning how to develop culturally-appropriate preventive measures, and how these health threats are understood from local perspectives. In Belize, health policy makers have only been marginally effective in managing infections and possible mosquito vectors, and the Belize Ministry of Health has declared Zika endemic in multiple regions of the country, including Caye Caulker Island which is the focus of this research. I argue that despite its declared endemic status, Zika infection is not perceived as a true health concern by members of affected communities which are in most need of state health interventions. This is due to the state's contradictory approach to managing health needs. On the one hand, the Belizean government increasingly implements neoliberal reforms that limit available services in poor communities, which are disproportionately affected by Zika because of inadequate public waste and water management, and instead focuses on keeping the tourist areas clean. On the other hand, the state engages in intensive reproductive governance by targeting women as responsible for avoiding pregnancy and Zika, while at the same time restricting reproductive healthcare access, in particular abortion services. This thesis, utilizing ethnographic and Geographic Information Systems fieldwork conducted primarily in 2017, explores how community perspectives of Zikarelated health risk and consequences are shaped, as well as how state health interventions to stem Zika are understood in the community and by the healthcare providers. Caye Caulker's popularity as a tourism destination also raises questions about cross-border disease transmission and state interventions not just on the island, but internationally. I also consider how critical 
medical anthropology and feminist analytical approaches are useful in exploring these questions. Zika's continued status as an emerging infectious disease, and quickly becoming an endemic one in multiple countries, calls for new research on these topics, especially in regions that see little attention in global public health scholarship.

In 1947, researchers identified a previously unknown virus in a sentinel rhesus monkey host in Uganda, shortly afterwards naming it after the Zika forest in which it was found (WHO 2018a; Singer 2017). Throughout the ensuing decades this supposedly mild virus continued to spread to other geographic regions, countries, and continents while receiving little attention in scientific communities. This global spread, also known as secondary or travel-associated transmission, is currently the main form of Zika transmission to the United States, in addition to its spread by sexual transmission. Zika infections in Belize however, as is the case for other Latin American countries, result mainly from a bite by a virus-carrying Aedes mosquito (United Nations 2017a). This process of animal-to-human infection—referred to as zoonosis—is directly relevant to sociocultural understandings of transmission and analysis of practices around humanenvironment interactions of concern to the research (Quammen, 2014; Singer, 2017). ${ }^{1}$ In 20152016, Zika transmission rapidly grew in the Americas, with first confirmed cases in Brazil. Increased rates of microcephaly in infants born to Zika-infected women during this time prompted the World Health Organization (WHO) to declare an international health crisis (WHO 2016). To date, Latin America and parts of the Caribbean have experienced the brunt of these cases.

\footnotetext{
${ }^{1}$ Some disagreement exists concerning the use of this terminology among health organizations based on differing definitions of what constitutes an "animal" in the context of zoonotic transference (Nading 2017).
} 
At the start of the outbreak in Belize in 2016, local media reported that the country was still "Zika free" and the state budget did not include any special Zika funding while the Ministry of Health declared it "will emphasize community cleanups and continued spraying across the country" (Humes 2016a). The Ministry expressed that spraying campaigns already focused on the same vectors of other mosquito-borne diseases, in particular dengue and chikungunya, would largely suffice to contain Zika if individual preventative measures such as condoms and protective clothing were used. It is important to note that at this time it was still unclear if Zika caused microcephaly or other congenital complications. When American tourists returning from vacation in Belize were diagnosed with Zika in April 2016, the Belizean Ministry of Health reacted by urging Belizeans to intensify preventative measures around their homes to eliminate mosquito breeding sights (Humes 2016b). However, these discourses remained ineffective, and by September 2016 Zika became endemic in parts of Belize according the Belize Ministry of Health. Soon after, the WHO also declared that "Zika is here to stay" for affected countries and advised a long-term approach in responding to this disease (McNeil 2016). WHO's rhetoric was not without its critics, who argued that focusing on individual countries may ignore the global nature of Zika and slow down international public health responses towards this infection. WHO's rhetoric is especially problematic for countries like Belize, which lack in resources to manage this ongoing crisis. The Gross Domestic Product per capita in Belize is USD 4,744 which is the third highest in Central America (World Bank 2017). However, Belize has significant income disparities ${ }^{2}$ between the richest and poorest strata of the society, with $41 \%$ of

\footnotetext{
${ }^{2}$ The Gini coefficient - the deviation of the income distribution - for Belize is 53 on a scale from 0 to 100 , where 0 indicates absolute equality and 100 represents absolute inequality. For example, the Gini index for countries with greater equality like Norway or Sweden is around 25, the United States is around 40, while for countries with greater inequality, such as South Africa, it is around 63. Thus, Belize's Gini coefficient is on the higher end of this spectrum. See: http://hdr.undp.org/en/content/income-gini-coefficient
} 
the population living at or below the poverty line (PAHO 2018). Under global economic pressures the Belizean government accepted International Monetary Fund loans and implemented structural adjustment programs which led to partial privatization of healthcare and pharmaceutical services (Richardson 2007; Uzwiak and Curran 2015). While the state continues to subsidize a national public healthcare system, the parallel for-profit system that emerged mainly adds services to urban areas. In contrast, the majority of Belizeans live in rural communities, with less than one physician per 1,000 residents in the country (WHO 2018b). It is therefore not surprising national polls show that the state has the fifth lowest satisfaction level out of 20 Latin American countries concerning the "availability of quality healthcare" (Government of Belize and Caribbean Development Bank 2012). 


\section{CHAPTER 2: LITERATURE REVIEW}

\section{Monitoring Pregnancy, Governing Reproduction}

Zika is most often an asymptomatic disease, meaning infected individuals express no symptoms. As the Centers for Disease Control and Prevention (CDC) outline, "For this reason, many people might not realize they have been infected" (CDC 2018). When symptoms are expressed they are generally mild and individuals may experience fever, rashes, headaches, joint and muscle pain, or conjunctivitis. Once infected, humans usually carry live Zika in their blood for about a week before antibodies develop, which most likely protects against future infection. ${ }^{3}$ However, the potential for active transmission of this virus can extend over a much longer period of time. For males, the CDC recommends male partners to abstain from sex or utilize contraception for at least six months after travelling to an area at risk of Zika, while for females they recommend similar guidelines for at least two months. This window of transmission is longer for males due to the prolonged viability of Zika in certain bodily fluids including semen.

Pregnant women in Belize may become eligible for a free Zika test at a public clinic if given a referral by a physician. However, the only public clinic on Caye Caulker Island, my field site, lacks the facilities to offer this free testing service. The closest testing facility is in the neighboring island town of San Pedro, but a round-trip boat ticket costs BZD 40 (20 USD), the journey to the clinic takes approximately 90 minutes one way, and there is often a long wait to see a healthcare provider. Therefore, women must assess if their concerns about possible congenital consequences of Zika justifies the economic and time investment of necessary

\footnotetext{
${ }^{3}$ Zika has already split into at least two distinct strains of this virus, which might compromise future immunity if such mutations continue to develop in this way. This is a constant risk with continued transmission.
} 
medical travel (Sobo, 2009). Belizeans may also seek this service at Caye Caulker's only forprofit private clinic, which offers tests for dengue or other mosquito-borne diseases, but patients must pay BZD 195 (95 USD). Since the minimum wage is only BZD 3.30 per hour (1.67 USD), obtaining passage to clinics is difficult and private testing for Zika is virtually unattainable for those most in need of these services (Lindauer 2014). Complicating this further, studies show that in Belize, "[d]espite a rising population and an increase in poverty, less government resources now attend to the social causations of poor health than 20 years ago" (Uzwiak and Curran 2015, 102). Neoliberal economic reforms are at the heart of these cutbacks and the declining attention to structural causes of ill health. Neoliberal principles, as geographer David Harvey observes $(2007,76)$, give market forces primacy in solving economic and social problems through a system in which privatization and business growth are assumed to be the primary drivers of improved quality of life, while "the social safety net is reduced to a bare minimum in favor of a system that emphasizes personal responsibility." This is particularly relevant in Belize, where, I argue, neoliberal policies contribute to limited Zika surveillance, management of possible vectors, and provision of reproductive healthcare access. In the context of abortion services, anthropologists Elise Andaya and Joanna Mishtal $(2017,52)$ additionally argue that "[j] ustifications for limiting access to abortion care are often framed in the logic of neoliberalism that rationalizes cutbacks in social services, including healthcare, and views the free market as antidote to a diverse range of social problems." This reduction of the social safety net in Belize's healthcare provision plays a direct role in how the state manages Zika treatment and surveillance, putting the onus of responsibility on individuals to monitor their own health, with implications for future generations in sites of active transmission. 
Compounding structural dilemmas, scientific consensus that Zika may cause congenital defects (Li et al., 2017; Ali et al., 2017) raises questions concerning access to reproductive healthcare, especially contraceptives and pregnancy termination. Health authorities' recommendations to postpone pregnancy may be problematic in Belize, where $48.6 \%$ of women in heterosexual relationships report using no method of contraception and only less than 5\% use male condoms (Statistical Institute of Belize and UNICEF, 2015 12). Among those who use modern contraception, the most common methods are female sterilization (17.4\%), birth control pills (11\%), and injectable hormonal contraceptives (10\%). While these contraceptive methods beyond condom use are effective for pregnancy prevention, none protects against sexually transmitted infections and Zika transmission. Relevant is also the fact that Belize has one of the lowest gender equality index levels in Latin America and the Caribbean region. ${ }^{4}$ This indicates that Belizean women face major barriers in political decision-making, education access, healthcare, and employment, and are therefore more likely to become dependent on their partners. Such economic and family planning barriers underscore the fact that women are being forced to make impossible reproductive decisions due to these discriminatory policies.

Further complicating this national healthcare discussion are major international and rights organizations, including the Pan American Health Organization (2016), which frame Zika treatment and access to abortion services within discourses of women's rights and human rights, and the Center for Reproductive Rights (2016) - an international legal advocacy organization focusing especially on cases of the right to safe and legal abortion. International actors and the circulation of rights-based discourses certainly matter at the country level. Such pressures, together with coordinated campaigns of feminists across Latin America, have resulted in

\footnotetext{
${ }^{4}$ See: World Economic Forum Report 2017: http://www3.weforum.org/docs/WEF_GGGR_2017.pdf
} 
liberalization of abortion in Mexico City and loosening of restrictions in Uruguay (Morgan and Roberts 2012, 248).

Medical anthropology may be able to play a role in this discussion as well. As Merrill Eisenberg points out, "The study of policy is inherently anthropological... The rules for behavior, laid down in either myth or policy, both reflect and produce social norms. Therefore, making policy is making culture" (Eisenberg 2011 97). Whether it be in the construction of infectious disease management and prevention policies, or restrictive governance of reproductive services, each will play a role in shaping accepted social norms and the agency of individuals navigating these sometimes interrelated contexts.

Belizean state's call on women to control fertility in light of Zika risks stands in stark contrast to its anti-abortion policy. Abortion in Belize is lawful only under limited conditions, including in cases when the woman's life, physical health, or mental health is at risk, or in cases of substantial fetal impairment (Women on Waves, 2017). This policy also restricts termination of pregnancy due to rape or incest and may be a driving factor in illegal abortion in the country (Jones, 2003). Two problems arise with such a restrictive abortion policy in the context of Zika. The first is by stigmatizing and criminalizing clandestine abortion, even to the point of imprisonment for life for those who perform illegal abortions or women who self-induce, the Belizean government may drive this practice into the shadows. If complications arise so too might questions of who provided the illegal termination, if it is reported as such. Secondly, maternal morbidity is a cause of frequent hospitalization of women in Belize, and a possible result of complications from illegal abortions (Women on Waves, 2017). Additionally, according to a global United Nations report, “[a]n abortion must be performed by a registered physician and authorized by two registered physicians" (United Nations, 2017b), which severely limits 
women's ability to receive abortion care even in the lawful scenarios, especially for those who must travel to distant providers and accrue cost to meet these requirements. Interestingly, according to the same UN report, the Belizean government considers fertility levels in the country of nearly three children per woman to be too high. This has led to the promotion of contraceptive services such as intrauterine devices and the practice of sterilization. However, contraceptive use remains low, and it is reasonable to expect that endemic Zika and the state's calls to avoid pregnancy as a way to prevent Zika-related fetal impairment may intensify illegal abortion seeking in Belize.

Therefore, Zika interventions will be challenging as policy makers navigate this polarizing discussion concerning abortion access, and they may instead opt for more visible and less contentious forms of intervention such as vector control. Anthropologists Lynn Morgan and Elizabeth Roberts have theorized such competing forms of policy-level and advocacy dictates as a form of reproductive governance, an analytical approach that "allows for the examination of how the subject making powers of moral regimes directed towards reproductive behaviors and practices are fully entangled with political economic process" $(2012,244)$. Under global economic pressures, neoliberal Western conceptions of biomedicine are becoming increasingly embedded in the way governmental bodies tend to approach health. Morgan and Roberts go further to claim that neoliberalism must be understood as influencing reproductive governance, despite Latin American countries not uniformly adopting "market-oriented neoliberalism" (2012, 246). With Belize offering state-subsidized universal healthcare, it would appear that this case is an exception to this international trend. However, as Beth Uzwiak and Siobhan Curran (2015, 111) demonstrate, Belizean healthcare is currently undergoing rapid neoliberal reform, especially 
affecting the "women and poor who become pathologized for poor health and the target of behavioral intervention."

In addition to these gendered effects, market-driven rationales also shape infectious disease healthcare. Under global economic pressures, neoliberal Western conceptions of biomedicine are becoming increasingly embedded in the way governmental bodies tend to approach health. As Nancy Scheper-Hughes and Margaret Lock observe, "[h]ealth is increasingly viewed in the United States as an achieved rather than ascribed status, and each individual is expected to 'work hard' at being strong, fit, and healthy. Conversely, ill health is no longer viewed as accidental, a mere quirk of nature, but rather is attributed to the individual's failure to live right, eat well, and exercise, etc." $(1987,25)$. I argue that this reasoning directly relates to how health policy is shaped in relation to vector-borne infectious diseases, in particular Zika, as individuals are made responsible for monitoring their own health given limited state engagement in public services. Paul Farmer takes this perspective a step further, linking neoliberal policies and discourses with structural violence in the form of lacking systems of care and resources $(2005,16)$. Adding to this discussion of unequal policy dynamics that put undue pressure on the most vulnerable, it has been found that "The critical medical anthropology approach involves an examination of how power structures impact health and healthcare systems and an assessment of the role of power and unequal access in the making and enforcement of policy" (Eisenberg 2011, 99). An examination of responses to Zika as an emerging disease therefore necessitates a critical medical anthropology and feminist analyses of the political and moral governance of state's subjects, as Zika's presence creates new challenges for individuals navigating inadequate policy interventions and seemingly-depoliticized reproductive discourses which focus on women while denying them full access to family planning care. 


\section{Vector Control and Surveillance}

While still a territory of Great Britain, Belize ${ }^{5}$ aided by UNICEF began organized vector control efforts with indoor spraying starting in 1950. This annual DDT spraying of households was relatively successful, leading to a reported $80 \%$ malaria burden reduction by 1957 and a near disappearance of malaria in Belize by 1963 (UCSF Global Health Group 2015). This accomplishment did not last long, as the Ministry of Health ceased regular spraying, instead opting for fumigation as a reactionary management strategy when mosquito populations increased in size. In the subsequent decades malaria expanded due to additional factors, including an influx of refugees from endemic countries, budgeting constraints, and increasing awareness of DDT's (the chemical used in fumigation) detrimental effects on health and the environment. As a result, vector populations have remained in a state of flux. Despite these limitations, Belize has largely been successful in managing the malaria-carrying mosquitoes of the genus Anopheles, with the goal of complete regional elimination by 2020 (UCSF Global Health Group 2015). In fact, only 22 locally-transmitted cases were reported in 2013. However, the state has not been as efficient in managing the primary vector of dengue and Zika, Aedes aegypti.

Before Zika arrived, the Belizean state has had extensive experience in the management of dengue, which is endemic in every region of the country (Ministry of Health 2016). This is significant because current preventative efforts to control the spread of vectors have not been successful in stemming cases of this disease. Zika will most likely follow a similar trajectory, as certain regions have already been declared endemic by the Ministry of Health. Public health interventions to control Ae. aegypti are highly challenging due to multifaceted interactions

\footnotetext{
${ }^{5}$ Until 1973 this territory was considered "British Honduras.” Belize gained its full independence in 1981.
} 
between humans and this mosquito species living in close proximity. As outlined by the European Center for Disease Prevention and Control (ECDC), Ae. aegypti "thrives in densely populated areas which lack reliable water supplies, waste management and sanitation" (ECDC 2018). Anthropologist Alex Nading examining dengue fever in Nicaragua points to these complex socioenvironmental interactions in which "[d]engue's ecology was the product of an age of which trade was rapid, urbanization was uneven, and social and economic inequality was on the rise" $(2014,14)$. He argues that fumigation intervention efforts are inadequate because they ignore the intimate "entanglement" of the domestically-inclined Ae. aegypti mosquito with human populations. This dengue vector management dynamic is also evident in Belize where top-down spraying programs are often in reaction to already identified infection cases, thereby negating the notion of "prevention" in interventions designed by the Ministry of Health (Smith 2012, 67). Fumigation efforts can then act as a heuristic fix, reactively managing fluctuating populations of mosquitoes without a long-term solution (Nading 2014). Anthropologist Merrill Singer (2017) has recently published research on the public health threats and implications brought about by this international Zika outbreak, especially in areas that are already affected by mosquito-borne infectious diseases. Singer argues that researchers must adopt perspectives that incorporate syndemic effects on health, given the potential for co-infection of mosquito-borne diseases, and asserts that "[a] syndemic approach draws attention both to the flow of changes in the socioecological conditions that shape everyday risk and vulnerability, including anthropogenic changes in environments and climates, and to the dynamic nature of disease ecology..." (Singer 2017, p. 5). Acknowledging syndemics is especially important to scholarship concerning infectious diseases in that it takes on a multidimensional perspective, illuminating the role we play in the spread and impact of epidemics on a daily basis, including overuse of 
antibiotics in humans and animals, occupying previously uninhabited geographical locations, and also changing our planet's climate (Singer 2015, p. 14).

Since Belize's first officially identified Zika case in May 2016, health officials have been overburdened due to a lack of facilities to monitor and address Zika cases, and test samples taken at public clinics must be sent out of the country for analysis (PAHO, 2017). Anthropologists have highlighted that such structural inadequacies in coping with recent global epidemics are impacting health and wellness, especially in poor or rural areas lacking access to health-related infrastructure (Farmer, 2014; Alley and Sommerfeld, 2014). Brown et al. (2012, 255) have additionally argued that socioeconomic inequality and disease distribution patterns are intricately linked, putting marginalized communities and individuals at increased levels of infection risk. This vector dynamic and structural problems are especially problematic in Caye Caulker, as the Belize Ministry of Health has declared this island to be an endemic site of Zika transmission (San Pedro Sun, 2016). The intersection of socioeconomic disparities and disease pathways is an important lens with which to conduct research of the Zika virus in local communities. This approach is especially useful considering the prevalence of possible vectors in Belize as well as the fact that Zika is usually asymptomatic or mild, making it difficult to detect and manage (CDC 2017a). A critical anthropology concerned with local perspectives as well as structural factors affecting management of the Zika virus may highlight key challenges with regards to public health policy and discourses around this disease, therefore, potentially informing policy, including reproductive policy, to promote health and wellness for affected communities.

Building on these interrelated topics, I additionally turn toward a growing body of literature involved with issues of human-mosquito interactions, as well as ecology. While anthropology has been relatively slow to produce literature on Zika, public health scholars 
utilizing Geographic Information Systems (GIS) techniques have produced a growing body of work on this emerging disease and related subjects (Rodriguez-Morales et al. 2016). GIS is a method to spatially orient and integrate different types of data which can be analyzed for deeper patterns or relationships, generally in the creation of geospatial maps. In the context of infectious diseases, GIS can potentially augment understandings of socio-structural and environmental factors compounding to affect health and wellness in anthropological research by filling such a niche. However, there appears to be an unequal distribution of the availability of GIS mapping services, especially in Belize, as scholars have shown that, "[s]cientific publications using GIS for development of epidemiological maps in ZIKV [Zika virus] lack in Latin America and Colombia, particularly at its north Caribbean coastal areas...which have been significantly affected by the 2015-2016 outbreak" (Rodriguez-Morales et al. 2016, 286). Despite this limitation concerning Zika surveillance and management in Belize, GIS specialists have utilized mapping techniques successfully to spatially orient mosquito vectors and disease risk factors for other transmittable diseases including dengue and malaria (Pope et al. 2005). Including Zika in this discussion will be crucial to promote proper management of vector populations as well as knowledge of local community perceptions of preparedness for outbreaks and eco-cultural factors that might impact the spread of this disease. Additionally, Bennet-Martin et al. $(2015,2)$ point out that "[e]nvironmental and social scientists as well as health and policy experts are increasingly realizing the value of GIS to evaluate spatio-temporal relationships between humans and the environment." Anthropological scholarship that utilizes GIS mapping techniques to visualize these possible links can potentially be used to better inform researchers as well as policy makers concerned with public health in international contexts. Rodriguez-Morales et al. $(2016,287)$ reach a similar conclusion concerning GIS and its ability to engage policy makers in 
the control of Zika in Colombia, and argue that the "[u]se of GIS-based epidemiological maps allow to integrate preventive and control strategies, as well public health policies, for joint control of this vector-borne disease..." Taking this into consideration, my research examined how community members understand current intervention efforts and how possible perceptions of health consequences are shaped by these interventions, in order to better inform researchers, vector control efforts, and public health policies that seek to address this disease. Specifically, I conducted research in Caye Caulker Island, Belize, where there is active transmission of the Zika virus, indicating it is being spread by local mosquitoes. Zika is a relatively new epidemic in the country, however, the Belizean state has already declared certain regions as endemic, meaning Zika outbreaks are expected to persist for years, and potentially emerge in previously unaffected communities. Thus, Belize is an excellent research location for examining these challenges, and possible global health and public policy lessons that can be utilized to quell its spread through effective medical interventions and vector management.

Zika presents multiple difficulties in Belize, making it a well-suited and timely site for this research. As of 2018, there is no vaccine, and new infection areas are emerging, despite efforts to manage the virus. Additionally, there is uncertainty among policy makers about how to manage vectors and human-environment interactions inherent to transmission, leading them to focus on surveillance initiatives. Key reasons underlying this uncertainty are a lack of organizational attempts integrating local perspectives and practices with public health policy as well as acknowledging the entangled nature of mosquito and human populations. Thus far, Zika is a new area of anthropological research, and my fieldwork is the first ethnographic study of this newly emerging infectious disease in Belize. Furthermore, little scholarly work has been conducted in Caye Caulker utilizing GIS beyond collecting data on marine debris and litter 
perceptions (Bennett-Martin et al. 2015). Therefore, questions remain for how to best implement impactful, culturally-appropriate measures towards the prevention of Zika and how this disease as well as the state health intervention efforts are understood. The purpose of this ethnographic and GIS fieldwork sought to contribute to such discussions, by investigating community perspectives concerning Zika and related interventions. 


\section{CHAPTER 3: METHODOLOGY}

My research design for this study included a mixed-methods approach which combined ethnographic fieldwork and GIS research. The three distinct but interrelated research questions that guided this project are:

(1) What are the experiences of communities in Belize with Zika interventions?

(2) To what extent do healthcare discourses and community preparedness initiatives shape perceptions of Zika-related health risk?

(3) How do different communities perceive Zika?

\section{Field Site Selection}

To answer my research questions, I conducted data collection utilizing ethnographic and GIS research methods in Caye Caulker, Belize, from June through August 2017, which built on preliminary fieldwork in 2016. Caye Caulker is a small island ${ }^{6}$ community off of the eastern coast of Belize with approximately 1,763 residents (Statistical Institute of Belize 2010), and is a popular destination for tourists seeking economical lodgings in close proximity to the Belize Barrier Reef. Almost every local business supports this industry in some capacity, and the Belize Ministry of Tourism played an active role when Zika was declared endemic by communicating to business owners about how to approach this sensitive topic with tourists. Mirroring what Smith $(2012,67)$ found in the mainland of Belize, island-wide fumigation is performed twice daily, in the morning and evening. The Ministry of Health in Belize inspects the homes of individuals positively diagnosed with a mosquito-borne disease and fumigates the surrounding

\footnotetext{
${ }^{6}$ Caye Caulker is split into smaller islands, a North and South, by a shallow water divide. However, the overwhelming majority of residents live on the developed South island which is the extent of this research.
} 
neighborhood where infection was likely to have happened, however this is not always "conducted proactively" (Smith 2012, 67). In other words, if there are no positive cases found by clinical surveillance, the Ministry of Health will not perform such intervention efforts beyond inconsistent fumigation by truck.

The Belizean government declared Zika to be endemic in Caye Caulker, which provided an excellent opportunity and field site for me to conduct medical anthropology of infectious disease research on this topic. Based on preliminary fieldwork conducted in 2016, I additionally had experience interacting with community members and knew this project would be feasible despite the short period of time I was to officially conduct my research from June to August 2017. Despite the time-intensive process of manual data collection, previous GIS scholarship in Caye Caulker concerning litter and debris demonstrated the viability of this choice of location for my research (Bennett-Martin et al. 2015). Given that Caye Caulker is a small island, this also greatly facilitated the ability of a lone ethnographic researcher to conduct such work, and given the prolonged period of time ethnography generally necessitates, I was able to thoroughly canvas accessible terrain and engage with key interlocutors on an often-daily basis. Because of Zika's endemic status on Caye Caulker and as an emerging epidemic in Belize, GIS research in this country also can potentially be used as a model for healthcare policy at the national-level and internationally in other regions of infection for the management of this disease.

\section{Data Collection}

My data collection methods included: (1) participant observation, (2) semi-structured interviews, (3) GIS (litter, waste management, business, and standing water analysis), and (4) document analysis. I describe and justify each method below. I received Institutional Review Board (IRB) 
approval ID SBE-17-13005 to conduct this research on April 12, 2017. This approval can be found in Appendix A.

\section{1) Participant Observation}

Participant observation is an integral part of ethnographic fieldwork, in which "[p]eople's actions and accounts are studied in everyday contexts, rather than under conditions created by the researcher" (Hammersley and Atkinson 2007, 3). I conducted extensive participant observation on Caye Caulker island during the research period which included: riding with vector control workers on multiple occasions during fumigation, spending time almost every day to "hang out" with a range of community members on their off-time from work or at bars and restaurants, following up with business owners or workers and other local contacts, daily walking to multiple communities on the island, and participating in an "Island Cleanup" day organized by the international non-profit development and marine conservancy NGO Frontier. ${ }^{7}$ While I did not keep a log of my daily hours in the field, I estimate I spent approximately four to six hours on average each day interacting with the community. Additionally, I attended every major event on Caye Caulker during my fieldwork. Events included: the annual and multi-day Caye Caulker Lobster Fest which serves as a major time for tourism and commerce, multiple "Full Moon" parties hosted by local establishments, and a new addition to the island called the Caye Caulker Health Fair which organizers aim to make an annual event. Participant observation allows the collection of "data in naturalistic settings by ethnographers who observe and/or take part in common and uncommon activities of the people being studied" (DeWalt and DeWalt 2011, 2). This was an appropriate method of conducting fieldwork in local communities and answering my

\footnotetext{
${ }^{7}$ I performed multiple guest lectures for this organization concerning the Zika virus in Caye Caulker as organizers expressed interest in educating volunteers about the current situation on the island based on my preliminary analysis. See their website: https://www.frontiergap.com/
} 
research questions because it afforded an emic perspective into everyday activities and behaviors through extended periods of fieldwork (Fetterman 2010, 39). My focus on everyday activities taking place on Caye Caulker provided a window into sociocultural perspectives that are not generally possible with more structured research techniques or research from afar (DeWalt \& DeWalt, 2011). I utilized a "big net" approach, interacting with local community members and building rapport with new contacts over time (Fetterman 2010). Throughout my fieldwork, I took detailed fieldnotes in a notebook and via the Samsung Memo mobile telephone application.

2) Semi-structured Interviews and Informal Conversations

My rapport building additionally facilitated interviews with research participants. I conducted 15 semi-structured interviews and held 23 informal conversations with participants. Recruitment will be outlined below. I approached my interview participants with a prepared and IRB-approved list of questions in the form of an interview guide tailored to the individual and sample population. Semi-structured interviews, while guided with a set of open-ended questions, allowed me the ability to ask unscripted questions that may arise during discussions. DeWalt and DeWalt comment on the flexibility of this approach by stating, "Semi-structured interviews are verbal approximations of a questionnaire with explicit research goals" $(2011,40)$. This non-rigid interview approach was appropriate because it allowed for new avenues of conversation to arise off-script that were pertinent to my research as well as my participants' interests, which afforded a richer depth of answers than a structured interview. Due to participant wariness of governmental surveillance, including the Ministry of Health, all interviews were conducted without the use of a voice recorder. Such wariness was surprisingly uniform among diverse members of the community. Thus, conversations during interviews were all hand-written in a notebook and later transcribed to Microsoft Word. Likewise, I collected data during informal 
conversations largely during participant-observation with the consent of each individual, most often through the Samsung Memo mobile telephone application or via notebook. All participants interviewed were assigned pseudonyms to protect their identity.

\section{Sampling and Recruitment}

I collected data with 34 research participants in three sample categories described in the following section. I used purposeful sampling method to seek out participants from particular occupations (e.g., vector control workers), and snow-ball (respondent-driven) sampling to enlarge my sample within each category (Bernard 2006:192-3). I sought to approach data collection holistically from several perspectives and provide as accurate of a representation as possible given the constraints of limited fieldwork time. 
Table 1: Sample Characteristics

\begin{tabular}{|c|c|c|c|}
\hline Medical Professionals \& Policy Makers & Number in Study & Male & Female \\
\hline Physician & 2 & 2 & 0 \\
\hline Nurse & 1 & 0 & 1 \\
\hline Pharmacist & 2 & 0 & 2 \\
\hline Policy Maker & 2 & 0 & 2 \\
\hline Health Inspector & 1 & 1 & 0 \\
\hline Total Participants in Sample Group \#1 & 8 & 3 & 5 \\
\hline \multicolumn{4}{|l|}{$\underline{\text { Vector Control \& Waste Management }}$} \\
\hline Waste Collector & 3 & 3 & 0 \\
\hline Vector Control & 2 & 2 & 0 \\
\hline Total Participants in Sample Group \#2 & 5 & 5 & 0 \\
\hline \multicolumn{4}{|l|}{ Caye Caulker Community Members } \\
\hline Business Owner & 9 & 4 & 5 \\
\hline Resident (Non-Business Owner) & 12 & 5 & 7 \\
\hline Total Participants in Sample Group \#3 & 21 & 9 & 12 \\
\hline
\end{tabular}

Group 1: Medical Professionals and Policy Makers

I recruited eight Belizean medical professionals and policy makers for semistructured interviews in addition to informal conversations. Caye Caulker Island has two healthcare facilities, a governmental public clinic which services the majority of islanders and a private forprofit practice. Each only has one doctor, with a small nursing staff at the public clinic. I 
interviewed each doctor to elucidate what was being done in clinical settings to address Zika as a health concern and to follow up on new information I acquired in the field. This resulted in multiple interviews with the same individual or check-ups to see if there were any new cases or developments relevant to my research. I made contact with multiple nurses at the public clinic, however, only one was available for an extended interview. Nursing staff complained of being overworked, especially with the public clinic being closed on the weekends, so it was difficult to find a time that worked for both parties involved. Each interview with health professionals was conducted in their office where they felt most comfortable discussing this potentially sensitive public health topic.

The island additionally has two pharmacies, each a short-walking distance to one of the clinics. I interviewed the owners of each business multiple times in their respective locations as it was common practice for individuals to come in asking for free medical advice, ensuring short semistructured interviews were not disruptive of their overall daily routine. One of these pharmacy owners also served as a medical advisor for the Caye Caulker Village Council concerning policy decisions and served as a key informant providing insight to both of these roles. One additional policy maker was included in this sample group who had a direct role in the implementation of waste and vector control interventions. I conducted my interview with her at the Village Council and this meeting also served as an opportunity to exchange information I had acquired based on my multiple months in the field. The final member of this sample group included a Belize Ministry of Health inspector of health. He had travelled from the mainland to Caye Caulker as part of an outreach initiative during the Caye Caulker Health Fair held in July 2017 despite making weekly inspection trips to the island. I approached him for an interview 
during participant observation at this event at the "Vector Control Booth" he was organizing, as this venue was conducive to extended individual discussions.

\section{Group 2: Vector Control and Waste Management}

I recruited three waste collectors and two vector control workers. I included this population to investigate perceptions of what was being done to control mosquito populations and factors involved with their active breeding. Additionally, the island's "vector control vehicle" is also the garbage truck during off-hours of fumigation leading to a natural overlap in these two communities of practice. In my sampling waste collectors were recruited for informal conversations and semistructured interviews through interactions facilitated by participant observation and often these discussions were conducted when they took a break from work. Additionally, I questioned vector control workers during my time conducting participant observation while "riding along" during fumigation as we would be in the vehicle for multiple hours at a time. One of these individuals was also a waste collector providing a window into perspectives for both.

\section{Group 3: Caye Caulker Community Members}

In order to gauge local perspectives on Zika interventions and health consequences I recruited 21 individuals for semistructured interviews or informal conversations, largely through participant observation. With my wide-net approach to collecting contacts my research interests also travelled by word-of-mouth to friends and family of individuals I spoke with facilitating further recruitment. I defined community members as Caye Caulker residents, which also included local business owners, to investigate what role individuals perceived Zika to play on the island's tourism economy. I recruited nine business owners and 12 non-business owning 
residents, for a total of 21 participants in this group. To limit overlap I did not include Groups 1 and 2 in this sample group size despite their local residency.

3) Geographic Information Systems

I conducted GIS mapping of waste and waste management, businesses, and standing water to better understand environmental and structural risk factors of mosquito breeding in the Caye Caulker. Clarence Gravlee claims that, “[m]edical anthropology's holistic and integrative approach to human experience enriches our understanding of sickness in health, but it also poses a challenge in attempting to delineate the range of research methods relevant to the field..." (Gravlee 2011, 69). I would question the word "challenge" in this context, as I believe this potential for integrative research and holism does not need to be "delineated," as innovative techniques that are relevant to specific research endeavors can provide a deeper level of meaning to anthropological concerns.

Specifically, I conducted GIS mapping of litter and standing water to better understand environmental and structural risk factors of mosquito breeding in the Caye Caulker community. GIS can augment ethnographic research with additional data on socioecological factors such as the management of standing water and waste distribution that influence the prevalence and impact of infectious disease agents (El-Zeiny et al. 2016; Rodriguez-Morales et. al 2016). Additionally, Wen et al. (2015) approach GIS mapping of mosquito-borne disease risk from an urban ecology perspective incorporating the interconnectedness of mosquito and human populations reminiscent of Nading's (2014) anthropological discussion of mosquito entanglement. Building on this scholarship, GIS complemented my fieldwork by spatially orienting possible mosquito vector locations and the scope of transmission pathways. To investigate possible disparities in waste management infrastructure in rural and urban areas, I 
also manually collected data on the spatially distribution of businesses on the island. As Fetterman $(2010,12)$ highlights, “Like writing, mapmaking forces the ethnographer to abstract and reduce reality to a manageable size." Therefore, the utilization of GIS field data collection was an appropriate method to examine how mosquito vectors and disease preparedness are interrelated by creating maps to visualize areas where mosquitoes could possibly breed such as in concentrated litter locations or standing water in proximity to human settlement patterns.

Before conducting fieldwork I created a geodatabase by defining appropriate feature classes and their respective attributes, including: Litter Type, Litter Quantity, Waste Management, Standing Water, and Businesses.

A. Litter Type: Mosquitoes can lay multiple larvae in objects as small as water bottle caps which makes the spatial mapping of such data vital to this project. Attributes that fell within this feature class included: Rubber, Styrofoam, Aluminum, Glass, Plastic, Building Material, Other (Viable Container), and Other (Non-Viable Container). I had originally intended to collect the litter type of every data point in my fieldsite but this task quickly became ineffectual due to the clustering of high quantities of litter and various materials. Because of this understanding, I stopped collecting individual pieces of litter after some time, and eliminated them from my data set. Plastics, construction material, Styrofoam, and other viable containers for larvae were virtually always present in my own data collection.

B. Litter Quantity: This feature class provided rich data pertinent to this project. I created three attributes to operationalize this field: Low (1-10 pieces of litter visible), Medium (11-20 pieces of litter visible), and High (21+ pieces of litter visible). The interpretation of the amount of litter based on numbers of visible pieces is a reasonable approach when 
the focus is on litter clustering, making my analysis useful as a proximate assessment for spatial risk of mosquito breeding. Besides the occasional bottle or other loose refuse, litter most often was found in clusters. Additionally, I eliminated the Low attribute from my data analysis as such debris often was not stationary due to high winds on the island moving them from collected locations. Litter clustering is, of course, a more accurate indicator of sites used for dumping purposes as well. Litter not always being stationary may also have affected the threshold boundaries between categories, however, large quantities of litter were often apparent as being over 21 individual pieces.

C. Waste Management: Based on my 2016 preliminary fieldwork in Caye Caulker, I created multiple attributes to assess waste management infrastructure in 2017; these included: Burn Site, Dumpster, Trash Bin, Recycle Bin, Bury Site, Other. My fieldwork necessitated some subjective interpretation of what I found in the field. For instance, I operationalized "Trash Bin" in my fieldwork to only include visible trash bins within the reach of community members and tourists without having to enter private residences or businesses. Large dumpsters and recycle bins were absent, and bury or burn sites necessitated entering private property. I did not incorporate such information for the sake of privacy as these are sensitive topics for residents.

D. Standing Water: This feature class only had one variable, Visible Standing Water. The small size of Caye Caulker was a great boon to standing water fieldwork data collection, as I was able to "check on" sites of visible standing water to see how long standing water took to evaporate or seep into the soft sands of the island. If it rained, I did not collect standing water data until a day had passed in such locations to eliminate these temporary sites from the data. 
E. Businesses: I created an additional feature class for "businesses" which I define for this project as a non-residential structure. Specific attributes for each structure under this feature class were created including: Open-air Stand, Religious Building, General Other, Grocery Store, Commercial Other, Hotel, Bar, Hostel, Hospital/Clinic, Restaurant. Some might challenge this lumping of religious buildings into the feature class "business," but for the purposes of this project I was primarily interested in locations where humans might congregate or gather as well as the spatial distribution of such structures on the island, so I utilize it as a catch-all term.

Ethnographic fieldwork can additionally supplement such GIS analysis with cultural analysis, exploring perceptions of Zika risk, who contributes to litter on the island, and potentially what can be done to alleviate this growing dilemma including engaging local governmental institutions or policy makers in this discussion. With this in-mind, to conduct my own ethnographic and GIS research in Caye Caulker I employed GIS software, Collector and ArcMap, utilizing my smartphone device and a GPS receiver ${ }^{8}$ to engage residents as participants in the research process as well as facilitate manual data collection.

\section{4) Document Analysis}

I conducted data collection and analysis of health reports and surveillance documents concerning Zika and other infectious diseases in Belize, in order to understand the state's management and interventions in an area of endemic transmission. This approach also included international health organizations and their responses to Zika. The Belize Ministry of Health, Centers for Disease Control and Prevention, World Health Organization, and Pan American

\footnotetext{
${ }^{8}$ I utilized the XGPS160 SkyPro GPS Receiver to collect GIS field data due to my familiarity with the device from previous GIS fieldwork and its seamless integration with Collector when paired with the mobile phone application Bluetooth GPS which synced my GPS coordinates with my smartphone. See: http://gps.dualav.com/explore-byproduct/xgps160/
} 
Health Organization all had useful data that are publicly accessible for this purpose.

Additionally, in order to adequately gauge perceptions of preparedness and perspectives concerning Zika, I analyzed local organizations' and media discourses concerned with this disease and comparable epidemics in Belize. With news sources being more publicly accessible than academic journals or governmental reports, this analysis was imperative in order to understand local perspectives of the Zika virus, as well as how institutions like the Belize Ministry of Health communicate down-stream. One form of communication the Belize Ministry of Health also provided was in the form of informational literature including pamphlets on the similarities and differences between Zika and other vector-borne diseases such as dengue and chikungunya. I collected such pamphlets written in Spanish and English in clinical waiting rooms as well as during the Caye Caulker Health Fair held in July, 2017. This venue was a new outreach initiative to provide Caye Caulker residents with information on different topics including contraceptive use, vector control information, as well as different types of diseases. Therefore, this form of manual document collection allowed me to acquire a range of pamphlets and information relevant to my research.

\section{Data Management and Analysis}

\section{Ethnographic Data}

My personal transcription of fieldnotes and interviews resulted in 44,582 transcribed words, 82 pages single-spaced, in a Microsoft Word document. ${ }^{9}$ I stored physical documents in a locked cabinet and protected digital material with passwords. Personal identifiers were not collected unless necessity required, such as facilitating further correspondence or interviews.

\footnotetext{
${ }^{9}$ I created separate documents for interviews and fieldnotes but have combined them here to provide an accurate account of the overall material.
} 
This information was stored in a temporary and password protected location which was later deleted.

After fully transcribing my interviews and fieldnotes during participant observation, I performed thematic coding utilizing Microsoft Word and a color coding schema. DeWalt and DeWalt define this process as "gradually (or quickly in a 'eureka' moment), the analyst begins to abstract a number of ideas and words contained in text into a single concept or a small set of related concepts" (DeWalt and DeWalt 2011, 189). This method was useful in that I was able to identify similar themes and subthemes from my notes, as well as group similar answers together between each interview. This also involved a process of creating code names for similar topics of discussion, as "a code name can reflect what the analyst sees as the central concept" (DeWalt and DeWalt 2011, 189). This is useful for two reasons. First, it allowed me to condense my own thought process to create categories that would be useful for analysis. Second, I was able to determine if certain topics receive more attention than others which might be telling of underlying biases in the questions that I asked participants that might affect collected data. This coding process allowed me to curate my findings, utilizing a word processor to facilitate the identification of themes or useful irregularities (DeWalt and DeWalt 2011, 189). Specific themes and subthemes included: 1) Cultural Context, 2) Reflexivity, 3) Risk Perceptions (Economic Risk, Health Risk), 4) Vector Control Perceptions (Top-Down, Grassroots), 5) Mosquito Breeding Factors Perceptions (Litter and Garbage, Water Management), 6) Zika Perceptions (Lack of Knowledge, Misconceptions, Knowledge, Apathy), 7) Development Perceptions (Development is good, Development is bad), 8) Government Intervention Perceptions (Neutral, Government is doing good, Government is not doing good), 9) Experiences with Zika and Disease, 10) Reproduction in Belize Perceptions (Women, Men, Healthcare Providers). 
My first findings chapter corresponds primarily with theme 10) which provided a rich amount of data concerning reproductive governance and perceptions of options available to individuals and healthcare providers providing treatment. This analysis additionally explored how gender played a role in individual experiences and perceptions of this disease. My second findings chapter which discusses ambiguities in clinical settings because of Zika and structural dynamics based primarily on interviews with healthcare providers which include themes 3), 5), 6), and 9), as well as GIS data analysis of mosquito breeding sites. My final findings chapter addresses differing conceptions of Zika-related health risk which draws on themes 3), 4), 6), 8), and 9) which is also complemented by GIS maps assessing the possible spatial risk of Zika transmission on the island.

\section{$\underline{\text { GIS Data }}$}

After returning from my fieldwork, I analyzed acquired GIS data and utilized this information to create multiple maps to supplement my ethnographic research. Specifically, I utilized the GIS software, ArcGIS version 10.4.1, to carry out analysis, which "provides a wide flexibility in how we conceptualize and model geographic features” (Bolstad 2012, 15). This flexibility and integration with the mobile app Collector made it a useful tool to input and analyze my data. My research concerning litter mirrored previous scholarship in Caye Caulker by Bennett-Martin et al. $(2015,557)$ whose "[d]ata analysis included an examination of the results based on raw counts of debris or data points observed (e.g., each data point may contain multiple pieces of the same type of material). Points, rather than lines or polygons, were chosen for GIS-based data collection efforts in order to provide a more spatially specific account...” Thus, while public health scholarship has been conducted in other geographic contexts to create geospatial maps utilizing kernel density (Wen et al. 2015) or other suites of clustering methods 
including Optimized Hot Spot Analysis (Esri 2018a), I have opted for a spatial visualization and quantification of individual data points for litter despite running kernel density analysis for businesses. With my focus on quantities of litter in specific locations this required simple modifications in symbology to reflect areas of increased litter density, e.g. bigger circles correspond to bigger quantities of litter. Additional symbology decisions included a demarcation of relevant objects in the environment for an assessment of mosquito risk factors such as standing water and (lack of) waste management receptacles. As described above, I additionally utilized the Kernel Density (Spatial Analyst) tool on the distribution of businesses to identify and draw boundaries around the "Rural" and "Urban" regions of Caye Caulker, which I supplemented with my experience in the field. I altered the symbology, specifically color, of this kernel density to more accurately indicate areas from low to high degrees of clustering. Finally, I created buffer zones around sites of litter and standing water with dissolving boundaries (Dissolve Type $=$ ALL) using the Buffer (Analysis) tool to allow for a continuous distribution in case of overlap. The opacity of each buffer was then altered to display the degree in which standing water and litter overlaid each other in these zones. For each map I created, the opensource basemap OpenStreetMap (2018) was utilized to provide a consistent background for my analysis on the island.

\section{Triangulation of Data}

The final stage of analysis involved the triangulation of all primary and secondary data from my outlined methodologies described above in order to build a coherent picture that answers my research questions (Fetterman 2010). The usefulness of such an approach to analysis was especially apparent in my creation of GIS maps as it supported community members' perceptions of where mosquitoes were most concentrated by spatially orienting risk factors. This 
further demonstrates the viability of integrative methods in research endeavors. I additionally performed secondary data analysis including institutional documents and media to establish key themes prevalent in public and state discourses and to compare discourses with actual practices at the local-level in policy interventions. Triangulation of different sources of data is critical for ethnographic validity, and for establishing the range of explanations and their relationship to each other (Fetterman 2010,94). Therefore, these data were useful in order to illuminate and contextualize my primary data, as well as to ensure I acquired as accurate picture as possible concerning sociocultural dynamics related to the Zika virus.

\section{Limitations}

There are two main limitations to this research project: limited time (impacts ethnography), and rainy season fieldwork (impacts GIS fieldwork). Due to the nature of Master's ethnographic fieldwork, I was limited to three months of time (June, July, half of August) to complete this research, which is a restrictive timeframe for anthropological fieldwork and impacts my sample size. However, this limitation was reduced by that fact that I built this project based on my preliminary work in 2016, and the fact that the island is small and has only two medical clinics, allowing me enough time to conduct research in both sites. Nevertheless, a longer research period would permit a larger community sample.

In terms of the GIS aspect of my work, one limitation was data collection in the rainy season (summer), and increased mosquito populations during this time. My GIS analysis of standing water may therefore be specific to this season, as I expected to see more clustering of mosquito breeding risk factors in this summer season. Such clustering is likely to diminish in the Belize dry season. This may play a role in vector control efforts during this period as well, with more fumigation interventions in response to increased mosquito populations when it rains. 


\section{Reflexivity}

During my fieldwork I was acutely aware of my role as a "white" foreign researcher in this location and how research participants might frame their answers to my questioning based on my positionality. This particularly manifested in interactions with community members and even policy makers or healthcare specialists, some of whom assumed my expertise with Zika, which I had to constantly reject as false. While this was concerning and posed a challenge on the one hand, the misperception of having expertise appeared to open doors to long meetings with physicians and other opportunities on the other hand. Additionally, my positionality as a man from the United States most likely played a role in how community members responded to my research questions and how open they were in discussing sensitive topics including abortion access in Belize. Everyone appeared forthcoming during conversations and interviews, however, I believe it is still important to acknowledge this possibly unspoken dynamic. This also presented no noticeable challenges in clinical settings including discussions with nurses, which were all women. However, I am still left wondering how women participants in my research framed their experiences with Zika and/or being pregnant during this health crisis to a sometimes overly curious foreigner. As I was additionally investigating perceptions of litter in Caye Caulker, I had to be careful not to imply or assign blame in local communities, this is also the approach that was taken during my preliminary fieldwork on the island. This was especially difficult after independently conferring with community members who sometimes blamed each other. This risk was minimized by carefully crafting my interview questions and being reflexive of my own positioning and power dynamics this potentially created.

My positionality as a perceived tourist by many islanders is also noteworthy. Many Belizeans, almost invariably men, operate as informal "Tour Guides." By this I refer to the 
practice of finding wealthy tourists to show around the island with the expectation of payment in alcohol or money. Men often jokingly assigned this label of "Tour Guide" to others who were seen constantly leading tourists around the island, especially foreign women, as there was an added expectation of compensation beyond money or free alcohol. I quickly learned about this dynamic from knowledgeable islanders who warned me to not "hang out" with certain individuals for this purpose. I found it sometimes difficult to discern a friendly smile from ulterior motives, with implications for how much information was given to me during conversations. This perceived status of the anthropologist-as-tourist also put me in difficult situations where I was a witness to cat-calling and harassment of women, especially foreign tourists, when "hanging out" with local men. I was particularly stricken with how this paralleled anthropologist David Hoffman’s (2006) experience as a "neophyte ethnographer" in Mexico where he describes being in situations where sexist and gendered language had to be utilized to stay in good favor with the men in his study. I did not participate in this behavior, but silence can also make you complicit, which led me to avoid certain individuals afterwards.

\section{Overview of Findings}

Now, Caye Caulker has been classified as an area endemic to Zika, which means that the disease is now there and it will be present for years to come. We will have sporadic outbreaks, just like dengue. So, in some seasons, you might have an increase in the number of cases and other seasons you might not. People who are appearing with these symptoms, we know now that it is Zika that is affecting the community (Dr. Javier Zuniga, Belize Ministry of Health, San Pedro Sun, 2016)

Despite statements such as these from the Belize Ministry of Health at a press conference on September 9, 2016, my research shows that Zika is not perceived as a major health concern 
for residents of Caye Caulker which are in most need of state health interventions, despite its declared endemic status in this region of the country. Factors influencing these perspectives are evident in three specific areas, each will correspond to their own respective chapter. In Chapter 4 I argue that reproductive governance in Belize shapes a gendered burden of care by putting the onus of responsibility on women, while at the same time promoting neoliberal policies that limit services. Previous scholarship in the country by anthropologists have already begun to address this issue, and my thesis builds upon their work. Specifically, to explore this topic I investigate the perceptions of men and women in Caye Caulker, as well as healthcare providers navigating these two interrelated health dynamics. In Chapter 5 I demonstrate that an ambiguous "official" and "unofficial" healthcare environment exists in which medical practitioners operate, thereby creating uncertainty about the effectiveness of Zika monitoring practices. I argue that multiple factors contribute to this context, including: neoliberal structural shifts, the usually asymptomatic nature of Zika, and its parallels with other vector-borne diseases when it does express symptoms. In Chapter 6 I explore the competing and conflicting health risk perceptions among community members, including between the perceived health impact of fumigation versus Zika and other mosquito-borne diseases, or concerning conceptions of the economic Zika risk versus its possible health risk. I argue that a neoliberal public health policy context creates conditions that force individuals to weigh these different conceptions of health consequences when coping with limited state interventions and low access to healthcare services. I conclude by providing an overview of how my findings interrelate, the implications of this research for multiple scholarly disciplines, as well as the future trajectory I see for Zika-related scholarship. 


\section{CHAPTER 4: "I THINK ZIKA ONLY REALLY AFFECT PREGNANT WOMEN": GENDERING CARE}

Previous studies in the western Cayo district of Belize found that neoliberal health reform has created a gendered burden of care, putting undue stress and responsibility on women despite not providing adequate health services to meet their needs (Uzwiak and Curran 2015). My findings demonstrate a similar trend in the context of Zika in Caye Caulker, Belize. The Belizean government's current approach to Zika can be described as a dual effort focusing on mosquito vector management and epidemiological surveillance by offering free testing services for pregnant women. However, based on my analysis this current Zika monitoring practice is inadequate to accurately gauge the possible scope of Zika's spread. The island has two healthcare facilities, a governmental public clinic which services the majority of islanders and a private for-profit practice. Each only has one doctor, with a small nursing staff at the public clinic. Pregnant women are eligible for free Zika testing if given a referral by a health practitioner at either clinic. I interviewed Anna, a local nurse, who explained, "The government is only testing for pregnant women. I call it "treat as you see." ${ }^{10}$ By this, she meant that if a woman is visibly pregnant she can get tested for free at a public clinic or hospital. However, the island's public clinic cannot provide this service. Only the private practice doctor has the facilities to test for Zika, which I have found is beyond the economic means of most islanders. It is also important to note that while BZD 3.30 is the state legislated minimum wage, some individuals in Caye Caulker claimed they were being payed even less than this minimum for their labor. An often-cited reason for this disparity was the heavy competition for limited jobs on the island allowing employers to charge less. Moreover, some might justify paying for the dengue rather than Zika test, since the former is generally perceived by islanders and physicians

\footnotetext{
${ }^{10}$ Interview with Anna (2017)
} 
as posing a greater health threat for individuals. This newly emerging disease context and healthcare dynamic puts women in a position where they must assess the risk of unexpected complications with their pregnancy and weigh it against the economic investment to pay or travel for medical care and testing elsewhere in the country.

The short-term benefit of paying for the private clinic test is significant as results can come as quickly as the next day after getting blood drawn. In contrast, those opting to travel for the "free" test must wait several weeks to hear back about a positive or negative result. My participant-observation around the commercial district of the island afforded frequent contact with a married couple, Mateo and Camila, ${ }^{11}$ who owned one of the local dive shops. Camila explained her Zika testing experience, "I went and got my blood drawn months ago. They sent it away to get tested, but I never heard back from them about results." Her husband Mateo jokingly chimed in, "We will probably know by 2029." When asked if it was common to not hear back or experience delays when getting results in public clinics and they both simply nodded in agreement.

This uncertainty further complicates family planning as couples or single women might not hear about possible congenital complications until later during the pregnancy, if at all. Such uncertainty creates potential obstacles for individuals attempting to navigate uneven health surveillance initiatives meant to understand the scope and reduce the risk of infection. Internationally, including Belize, women are the primary targets for governmental health discourses concerning Zika. With researchers linking this disease to congenital Zika syndrome, this raises questions over access to abortion in Latin America, especially in countries that have highly restrictive access to such procedures. Anna bluntly addressed this concern, "There are no

\footnotetext{
${ }^{11}$ Interview with Mateo and Camila (2017)
} 
legal abortions at all." I asked if this contradicts Belize's stated abortion policy, since the law provides concessions in order to save the life or preserve the physical or mental health of the woman, and economic and social circumstances may also be considered in allowing a lawful abortion. However, she clarified further, "It is extremely difficult to get one legally. Maternal mortality is high, and this law also contributes to underground abortions. You can really get an abortion anywhere [clandestinely]."12

Clandestine abortions are typically risky and unsafe as compared to clinical settings. Dr. Garcia, the private clinic doctor who used to also work in a public clinic in the Belizean mainland, reflected that it was relatively common for women to come in claiming they had a miscarriage despite showing signs an abortion was induced with pharmaceuticals such as mifepristone and misoprostol. The common use of pharmaceuticals to facilitate an abortion was mentioned to me by every medical professional and pharmacist on the island. ${ }^{13}$ Curiously, each provider claimed they would not personally prescribe it, and pharmacists mentioned they do not stock either medication unless given a prescription because they know of their "alternative usage." This would imply that women seeking to terminate their pregnancy in Caye Caulker must travel elsewhere to obtain these pharmaceuticals or utilize alternative methods to selfinduce. Roger, a health inspector from the Belize Ministry of Health, had much to say on this issue, "Yes, maternal morbidity is pretty high. If a woman wants an abortion the 'legal way' through a clinic she usually would have to travel abroad. Women know it's dangerous [to induce an abortion clandestinely]. I don't see why they just don't carry the baby to term, it's just safer. I

\footnotetext{
${ }^{12}$ Interview with Anna (2017), continued

${ }^{13}$ This finding is consistent with public health research which shows that in Latin American countries where abortion is restricted, women typically obtain (often from local pharmacists) and use mifepristone and misoprostol as a way to self-induce a termination (Lara et al 2006).
} 
know plenty of cases of mothers even throwing themselves down the stairs to cause a miscarriage." When asked if he thought that clandestine abortions might increase with concerns of microcephaly since there had been one clinically confirmed case in Caye Caulker, Roger responded, "I don't know. There have not been enough cases to create any kind of stigma. I think if a baby is born with microcephaly, the Belizean thing to do would be for the mother to not talk about it." When I pressed further to see if the government had any systems in place to help mothers with microcephalic infants he offered, "I mean, mothers can monitor their pregnancy for signs of microcephaly, but beyond monitoring I don't know what else there is to do."14

The Belizean government's current focus on monitoring raises further concerns about post-natal care, including physical therapy, for infants with congenital birth defects. In Brazil, for instance, much has been written about the limited access to transportation and resources for families seeking such therapies, which disproportionally puts the burden on women who are traditionally seen as the caregivers for children (Diniz 2017; Human Rights Watch 2017). Even if physical and other forms of therapy became available, and perhaps more importantly affordable for Belizean families, the burden of travel from an island to a mainland facility would make this an all-day event and perhaps not feasible for all women affected.

Women will certainly be disproportionally affected by this new development in Belize. However, health policy makers and organizations must be aware of how gendered discourses and intervention efforts can leave men out of the discussion and place undue responsibility on women. Dr, Javier Zuniga, Ministry of Health, outlined the government's current approach to Zika monitoring, "We are targeting pregnant women. We cannot tell a woman not to get pregnant, we would like to ask them to delay pregnancy and if they are planning to get pregnant

\footnotetext{
${ }^{14}$ Interview with Roger (2017)
} 
to please visit their health facility as soon as possible" (San Pedro Sun, 2016). Health

practitioners also noted that this monitoring practice for pregnant women is exclusionary to other groups of individuals, including men. Dr. Garcia expressed his frustration concerning men being largely ignored in government testing initiatives and outreach, instead opting to just perform Zika surveillance on pregnant women. He argued, "You are ignoring half of the possible cases. This makes men not care about Zika." 15 These inadequate surveillance practices that shape the perceived role of men in healthcare environments, especially in relation to reproductive topics, are reflected in other global contexts (Inhorn 2006, 351-352). ${ }^{16}$ Anthropologist Matthew Gutmann $(2011,55)$ claimed this creates a self-fulfilling prophecy where men believe they are not participants in this process despite generally holding the majority of policy-making positions. This gender disparity in governance also extends to Belize, where in 2012 a report released by the National Women's Commission with aid from the United Nations Development Program found only one elected woman in the Belize National Assembly ${ }^{17}$. This report further argued, “Women's representation in legislatures is as important as the realization of women's right to speak and be heard. It is also important, however, to ensure that women's concerns are effectively integrated into the policy agenda" (National Women's Commission, 2012, p.7). Both the shortage of women in health policy making and the omission of men in reproductive health

\footnotetext{
${ }^{15}$ Interview with Dr. Garcia (2017)

16 The focus on women in the epidemiological surveillance for Zika in Belize differs from recommendations by the Center for Disease Control (CDC) in the US. CDC's recommendations are directed at both women and men living in Zika-infected areas, including men with pregnant partners, men who are planning pregnancy with their partners and men who are not concerned about pregnancy, including precautions for travel, and sexual activity. Florida state guidelines also target men based on the data showing that even asymptomatic men's semen can remain infected for several months. See: https://www.cdc.gov/zika/men/index.html and https://www.cdc.gov/zika/intheus/floridaupdate.html.

17 There currently are three women in the Belize National Assembly as of 2018. See: https://www.nationalassembly.gov.bz/house-of-representatives/
} 
discourses contribute to inadequate approaches for managing major health concerns such as Zika.

There is an interesting relationship among islanders regarding spatio-temporal proximity to a pregnant individual and concern about infectious vectors and transmission. If no one in the immediate family is expecting to become pregnant or is currently pregnant, interviewed individuals largely are unconcerned about risk of Zika infection. This is despite the possibility of transmission to a pregnant woman through mosquitoes or other means. Chloe, a young woman accompanying her daughter in the commercial district of the island related: "I think Zika only really affects pregnant women so I am not worried now, but when my sister was pregnant I wore lots of repellant during her pregnancy." Anticipating my next question, she followed with, "The baby is okay though." 18 This concern focused on the time of pregnancy and proximity to women in the family also extended to men's perspectives. As a local fisherman Marko remarked during an afternoon siesta in his hammock, "I have two daughters, so I am pretty cautious [about Zika]. I make sure to have them spray when they go outside, and they sleep with mosquito nets. Some locals don't care though, and they don't spray." 19 These perspectives are emblematic of the common focus on women and the potential threat of Zika as it relates to reproduction.

In particular, states and international health organizations in their Zika response efforts have urged women to utilize contraceptives, abstain from sex, or "avoid affected areas" (CDC 2017b). Calling for couples to abstain from sex for up to six months is especially problematic as policies promoting abstinence have proven inefficacious and difficult to comply with (Diniz 2017, 114). Despite Belizean state's subsidies of modern contraceptive options, this focus on women is particularly difficult in poor and marginalized communities that lack access to

\footnotetext{
${ }^{18}$ Interview with Chloe (2017)

${ }^{19}$ Interview with Marko (2017)
} 
adequate healthcare and reproductive services. This new development in reproductive governance discourses and policy strategies has not changed the fact that, unless pregnant and given a referral, women in Belize must also pay to be tested for Zika. Rena, who owns one of the island's local laundromats, related her experience: "I self-diagnosed myself with Zika. Going to the doctor is pointless. They just waste your time and don't do anything." ${ }^{20}$ Therefore, more than half of the possible cases may be ignored or undetected by state surveillance practices, despite Dr. Garcia's original estimation. This raises further concerns about the effects of neoliberal approaches in which state's provision of healthcare is limited and abortion remains restricted, while women are targeted as responsible for avoiding pregnancy and Zika.

In this chapter, I have built on, and expanded from, the previous scholarship in Belize to demonstrate the extent of reproductive governance and a gendering of care in Belize despite this newly emerging disease dynamic in the country. These policies in practice put the onus of responsibility on women to monitor and prevent Zika infection while at the same time restricting reproductive services and decision making. With the cost of private clinic testing and additional structural boundaries further limiting the ability of families to test for this disease, these constraints have further implications concerning the ability for health specialists to assess the public health consequences and scope Zika transmission. Chapter 5 addresses this issue.

\footnotetext{
${ }^{20}$ Interview with Rena (2017)
} 


\section{CHAPTER 5: “OFFICIAL” AND “UNOFFICIAL” ZIKA: AMBIGUITIES IN THE HEALTHCARE ENVIRONMENT}

Despite Zika's declared endemic status by the Belize Ministry of Health in 2016, health providers hold conflicting opinions about this terminology. Dr. Alvarez, who operates the public clinic, observed, "Statistically for it to be considered endemic there have to be confirmed cases. As a doctor seeing symptoms, I can see there is Zika, but they don't get tested. So officially, Zika isn't endemic, but unofficially, it is endemic." 21 This ambiguous environment of "official" and "unofficial" cases, due largely to structural factors such as the cost of private clinic testing on the island and poor disease monitoring in the country, contributes to so-called ascertainment bias in clinical settings. Compounding this issue, Zika shares multiple symptoms with other vectorborne disease, which is reflected in the "Noh Get Bite" pamphlets the Ministry of Health provides the public clinic on the island (See Figure 1).

\footnotetext{
${ }^{21}$ Interview with Dr. Alvarez (2017)
} 


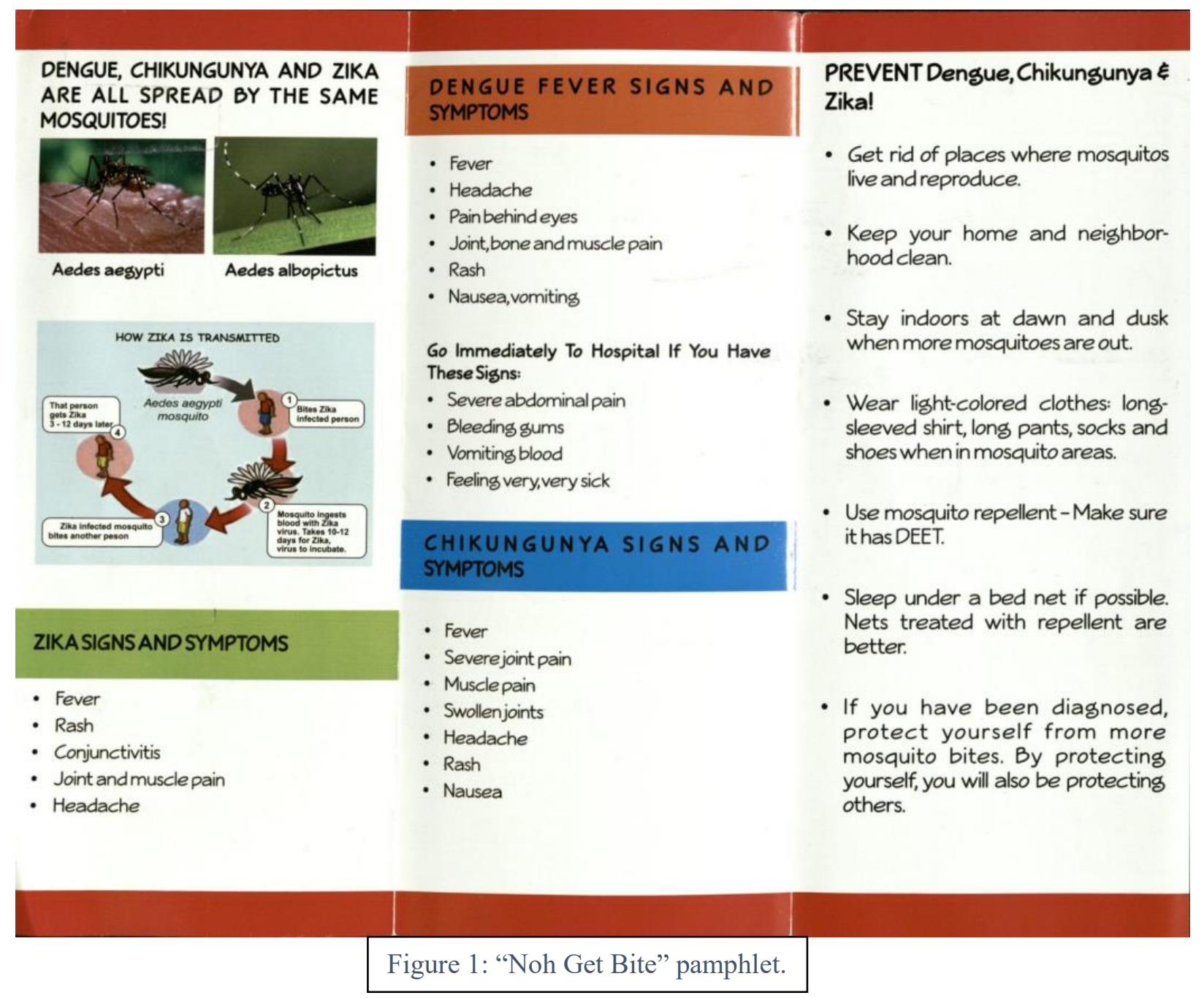

This pamphlet is framed in language that assigns personal responsibility to individuals so they may "Prevent dengue, chikungunya, and Zika," such as telling them to prevent mosquito bites by wearing long-sleeved clothes and staying indoors, while at the same time supposedly giving them the tools to assess and compare symptoms of very similar infectious diseases. Such uncertainty can also fuel conflicting perceptions of whether Zika should indeed be considered endemic to the island, with consequences for how community members assess the health consequences of this burgeoning disease and the need for testing. As Dr. Garcia revealed: "Information here is a one-way system. I diagnosed the first case of Zika, but I did not hear about microcephaly on the island until a patient told me [around April, months later]. In reality, 
nothing comes as a book tells you for diagnosis, especially with Zika being usually asymptomatic. They must be tested to make sure. Other diseases can be too similar. People tell me, 'Doc, I can't afford all 4 tests [for dengue, chikungunya, malaria, and Zika]', so they pick which diseases they want to test for. Most people can't afford to get tested here. Unfortunately, only people who could afford it were tested, so it most likely started earlier than first reported."22

Zika's declared endemic status on the island, coupled with its usually asymptomatic nature and parallels with vector-borne diseases, can then be seen as synergizing with structural factors to further create this ambiguous healthcare environment. This discussion mirrors aspects of Merrill Singer's $(2015,2017)$ syndemics theory, as vector-borne diseases do not necessarily occur in isolation. These potential disease dynamics are especially problematic with ecological and structural factors facilitating their spread, and multiple diseases can possibly co-infect individuals or mosquito vectors, further complicating diagnosis in clinical settings.

I argue that neoliberal structural policies are in fact contributing to Zika's endemic status, which is further exacerbated by the island's poor garbage disposal and water management infrastructure. Collection and removal of garbage in residential areas is a fee-based service not typically affordable to many residents, which contributes to pervasive littering practices. Illegal open-air "dump sites" are a common occurrence in these residential areas (See Figures 2 and 3).

\footnotetext{
${ }^{22}$ Interview with Dr. Garcia (2017)
} 


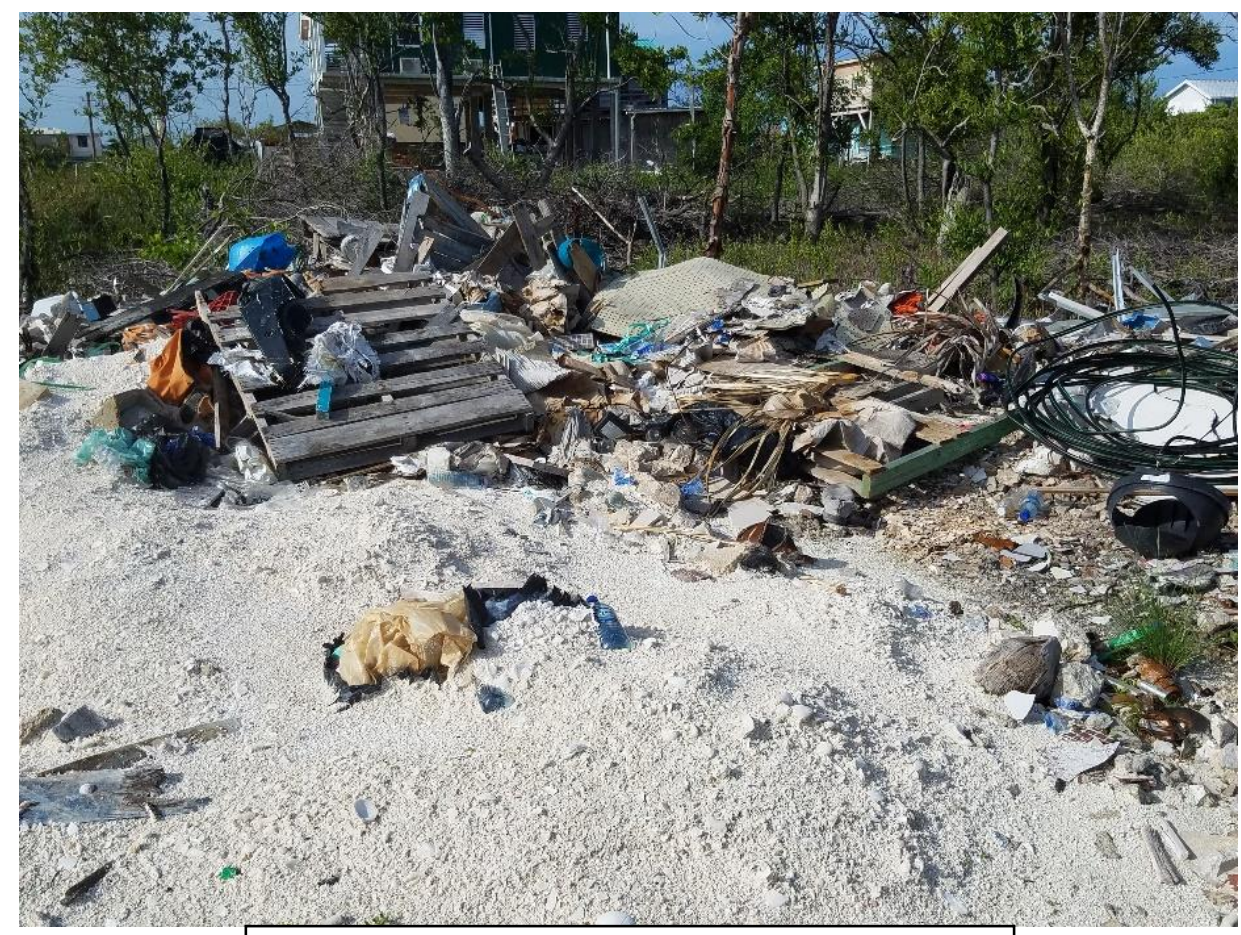

Figure 2: One of the many litter hotspots in residential areas. Photo: Deven Gray

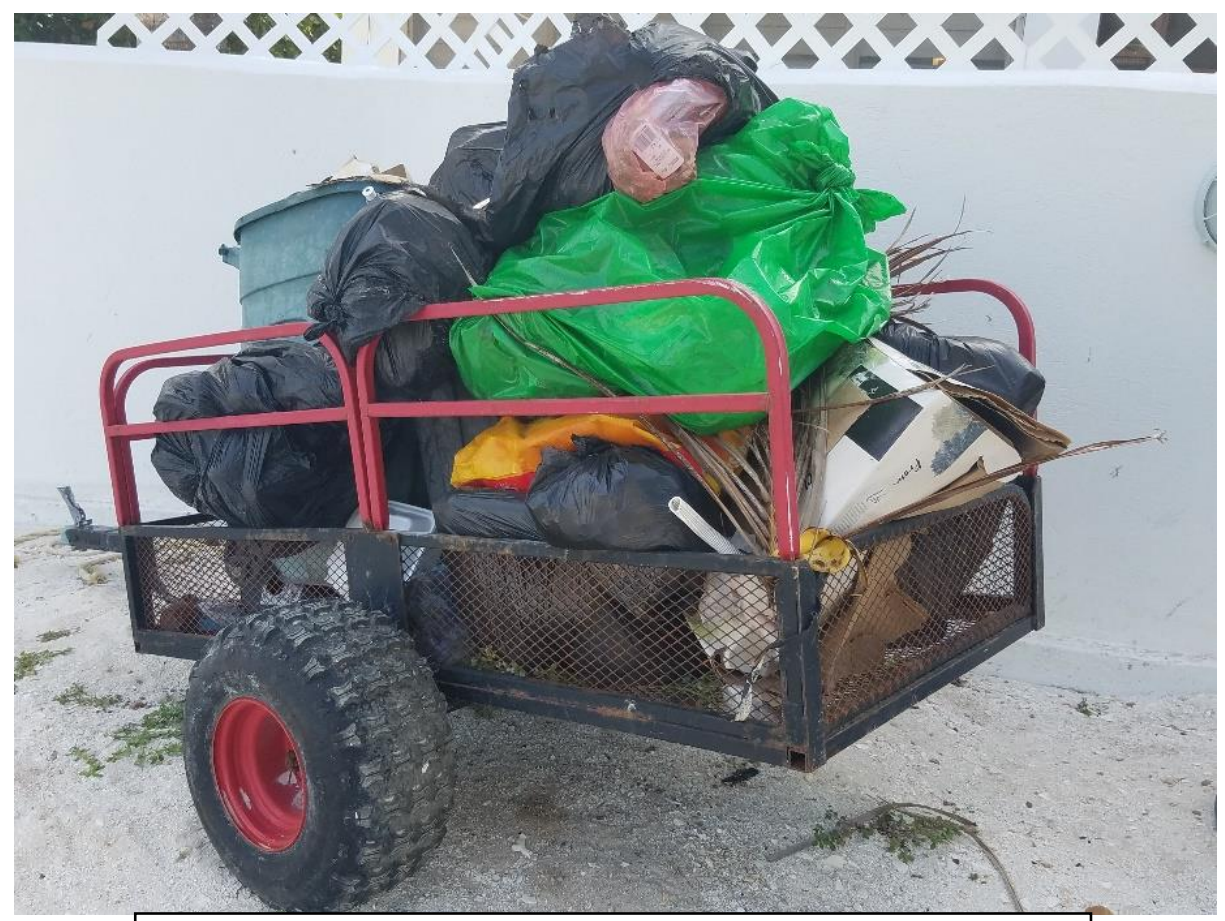

Figure 3: A loaded cart used by private garbage collectors. Residents must pay for this service. Photo: Deven Gray 
In contrast, commercial areas of the island have an abundance of garbage bins provided free by the state which are collected daily by the Island municipal authority, with colorful signs displaying "Keep Caye Caulker Clean" (See Figure 4). This demonstrates a priority by the local municipality to cater to tourists who frequent the beaches and resorts in this area. This is not a situation unique to Caye Caulker, as trash and recycling infrastructure is limited across Belize (Bennett-Martin et al. 2015).

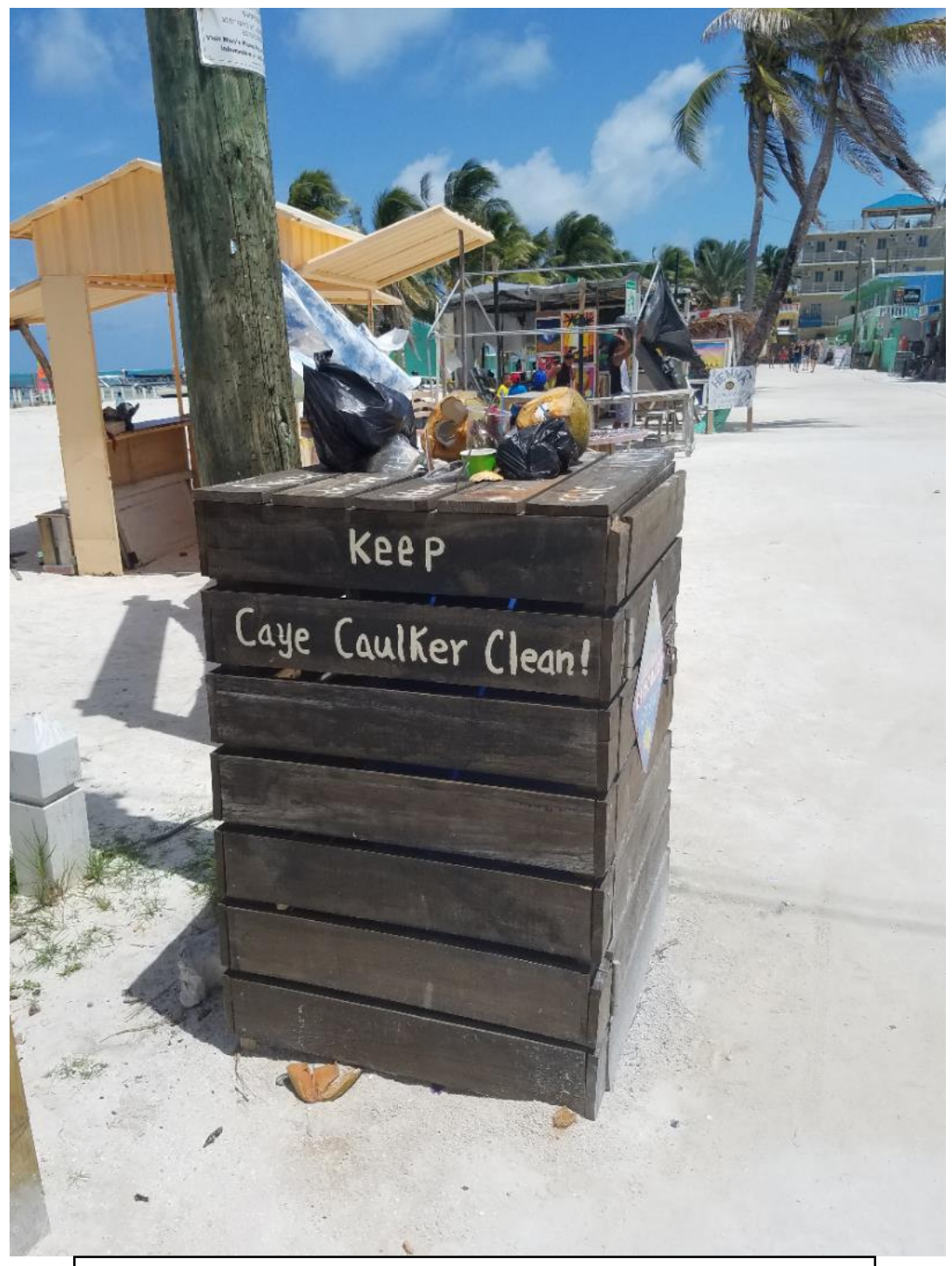

Figure 4: One of the government owned trash cans in the commercial district. Notice the small openings at the top to insert trash and to prevent household garbage bags from being deposited. Photo: Deven Gray 
The local municipality also provides water to Caye Caulker residents on a meter-based system - an expense that is substantial for most islanders. To subvert or offset this cost, community members actively store rainwater in open-air containers to utilize for everyday purposes such as cooking and cleaning. It is important to note that illegal dump sites are generally in close proximity to these containers. These coping practices contribute to the proliferation of mosquitoes and have been observed in other geographic contexts (Kendall et al., 1991; Nading, 2014; Arunachalam et al., 2010). This is especially a concern in the rural residential areas, as homes are often built on top of, or next to, mangroves which are known local breeding sites for mosquitoes. Moreover, when it rains, rural properties are prone to flooding and may hold standing water for multiple days. Community members know the largest populations of actively breeding mosquitoes are in the poorest regions of the island. In response to these perceptions, and because community members who live in these areas also know that vector control only comes when "mosquitoes are bad," residents practice grassroots methods of managing mosquito populations, including burning coconut husks to ward away adult mosquitoes and pouring used cooking oil in crab holes that are known breeding sites. With pervasive litter in the island's poorer regions, community members also repurpose litter as free land-fill to dredge mangroves around residential properties.

In addition to the possibility of disease co-presence in syndemics theory, Singer (2015, 244) argues that, "[s]yndemics, in short, are entwined complexes of biological, social, cultural, and often environmental factors." Such a perspective has even led to the development of what he has called ecosyndemics (Singer 2010). To visualize possible eco-social and syndemic factors influencing vector breeding and disease transmission on Caye Caulker, I created GIS maps that provide multiple avenues of collected data that contribute to this discussion. To do so, it was first 
necessary for me to delineate this island into two separate sections based on urban density and time spent in the field, which is displayed in the map legend as: 1) Urban - Commercial, and 2) Rural - Residential. This distinction is, in part, my own construction, but multiple factors on the island and my analysis support my decision. The first is the placement of the "Caye Caulker Rural South Office" which, of course, can be found in the southern portion of the island. Additionally, I performed Kernel Density analysis on the spatial distribution and concentrations of businesses (See Figure 5). Due to the nature of manual data collection some businesses were most likely missed, however this will be minimal due to my extended time on the island. It should also be noted that some small degree of clustering can be found in the South-East section of Caye Caulker, however these are largely hostels and hotels catering to tourists. 


\section{Kernel Density and Region Boundaries}

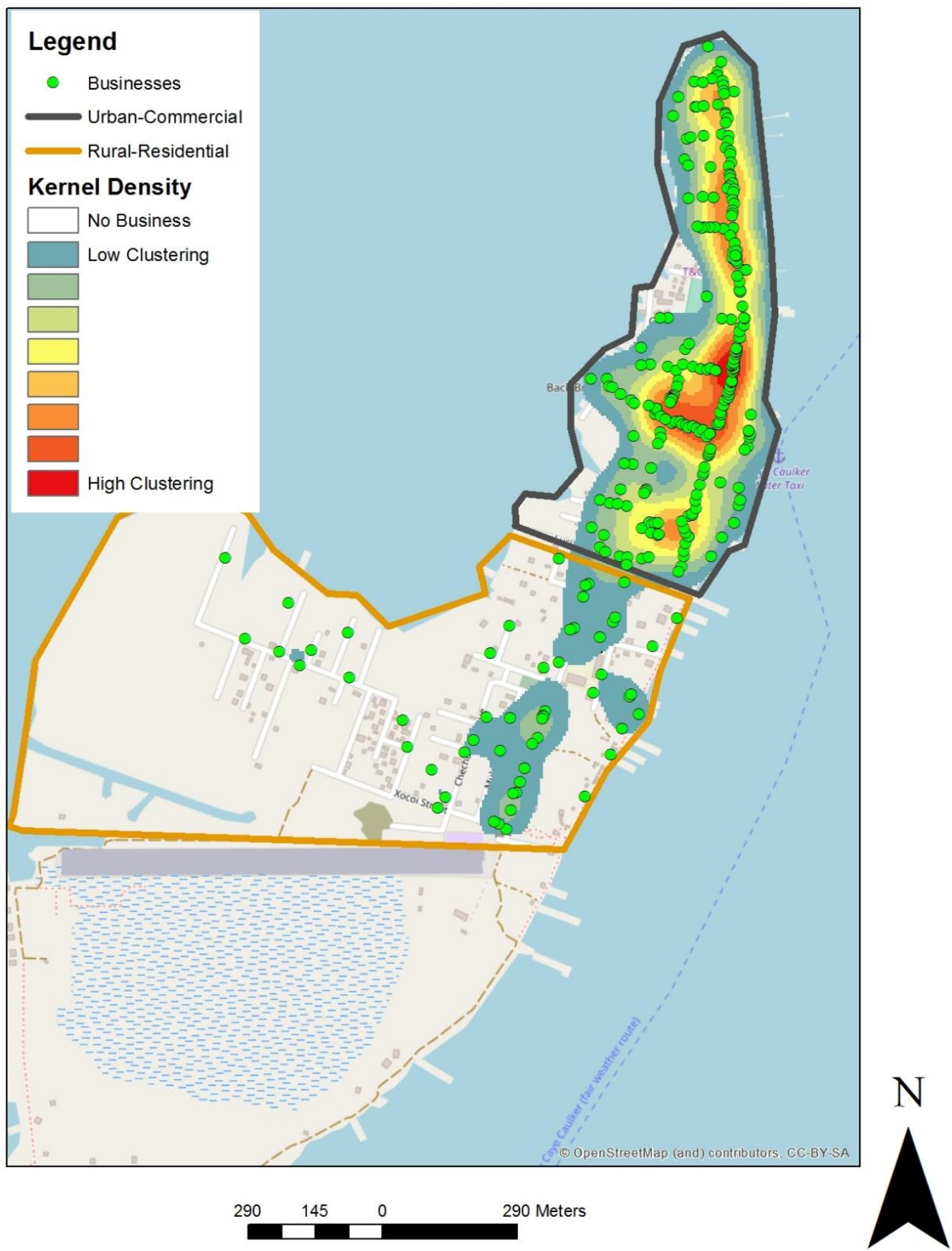

Figure 5: Kernel Density analysis of the distribution of businesses in Caye Caulker. Blue is least clustered while red indicates a high degree of clustering. 
As this Kernel Density analysis demonstrates, the highest degree of business clustering is found in the north region of the island. Kernel Density is an appropriate method to conduct such analysis as it calculates the density of point features, in this case businesses, and displays possible concentrations linearly from least clustered to most clustered (Esri 2018b). To clean-up this visualization I eliminated $($ color $=$ null) the first Kernel Density analysis section as a few data points were collected in the much less inhabited north island of Caye Caulker which stretched the density field obscuring the data. Finally, there is a single-road, Luciano Reyes Street, which stretches east-west, thereby cleanly separating these two halves. There are also private residences in the southernmost region of the island. However, due to private property restrictions limiting fieldwork, these buildings and the surrounding area around them were not included in my data analysis. There are likely no businesses in these regions. The large circular shape below the rural boundary corresponds to what OpenStreetMap indicates to be mangrove.

This geo-spatial distinction of Rural and Urban served as the foundation for other analyses, especially relevant to this thesis was the distribution of waste (litter), waste management (trash bins), and standing water. I have provided three figures below, the first is an overview of the entire fieldsite, with two additional maps which expand on each specific zone (See Figures 6,7,8). 


\section{Waste and Standing Water Distribution}

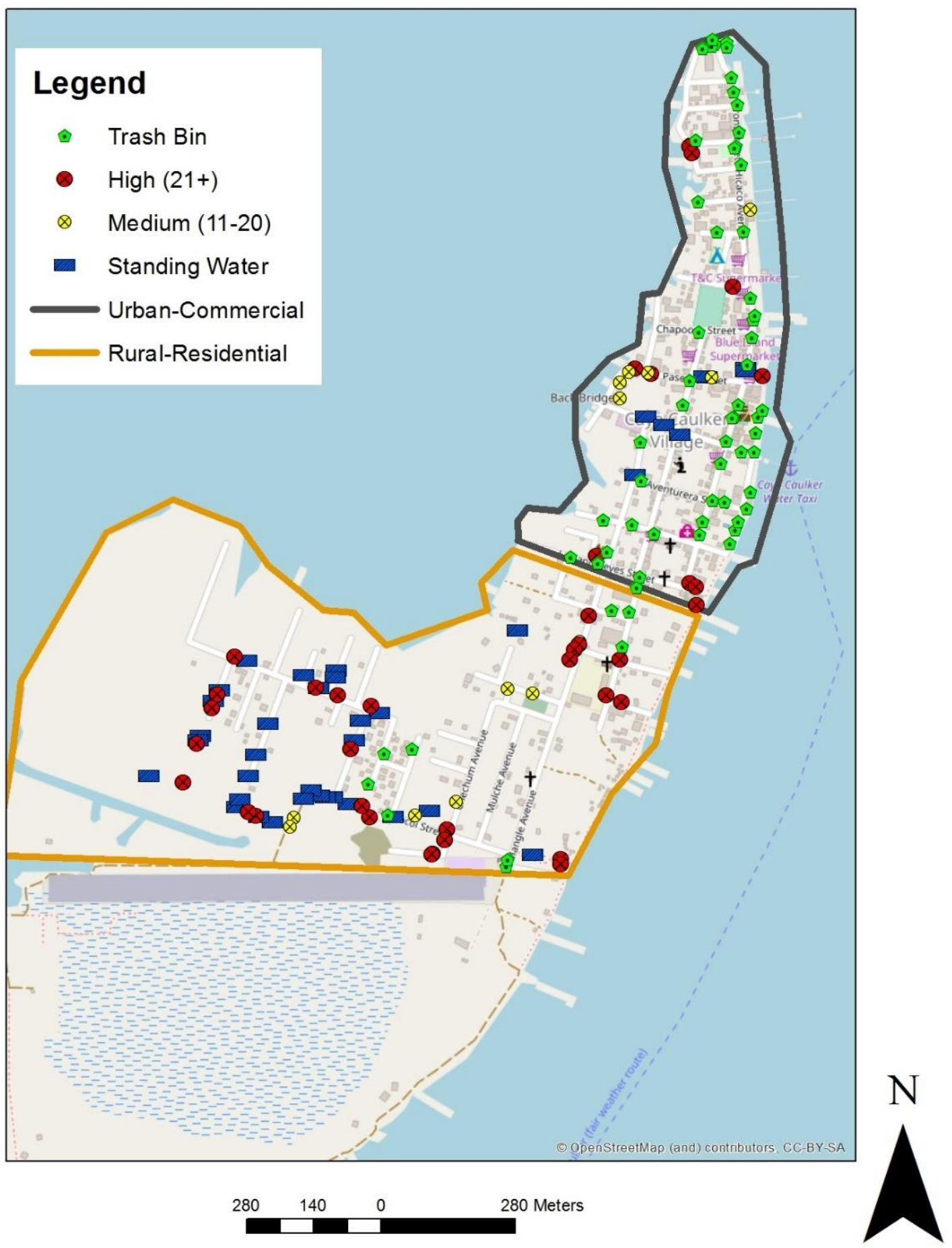

Figure 6: Overview of the distribution of trash bins, litter clustering, and standing water within both the urban and rural zones of Caye Caulker. 


\section{Rural Waste and Standing Water Distribution}

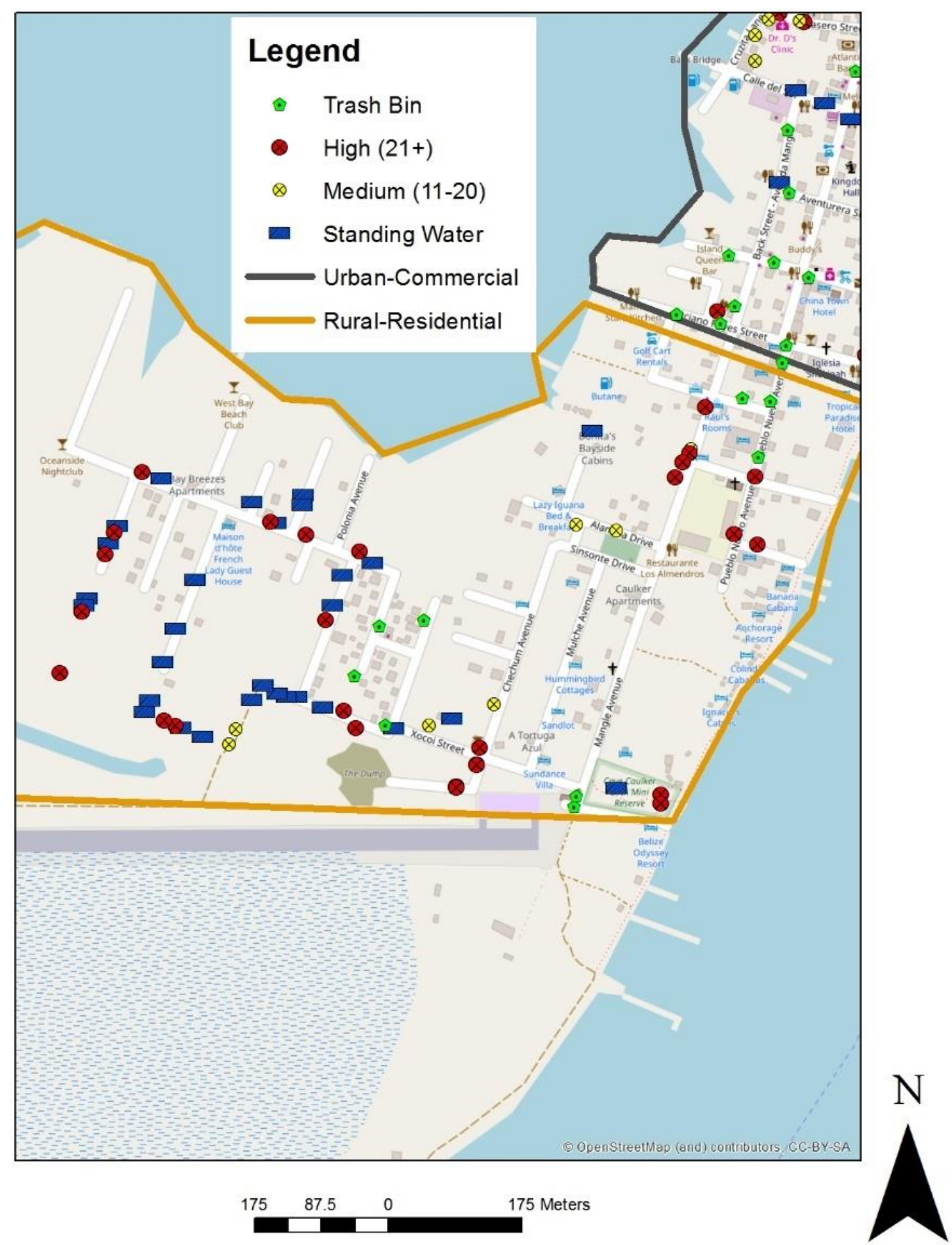

Figure 7: Distribution of trash bins, litter clustering, and standing water specific to the rural zone of Caye Caulker. 


\section{Urban Waste and Standing Water Distribution}

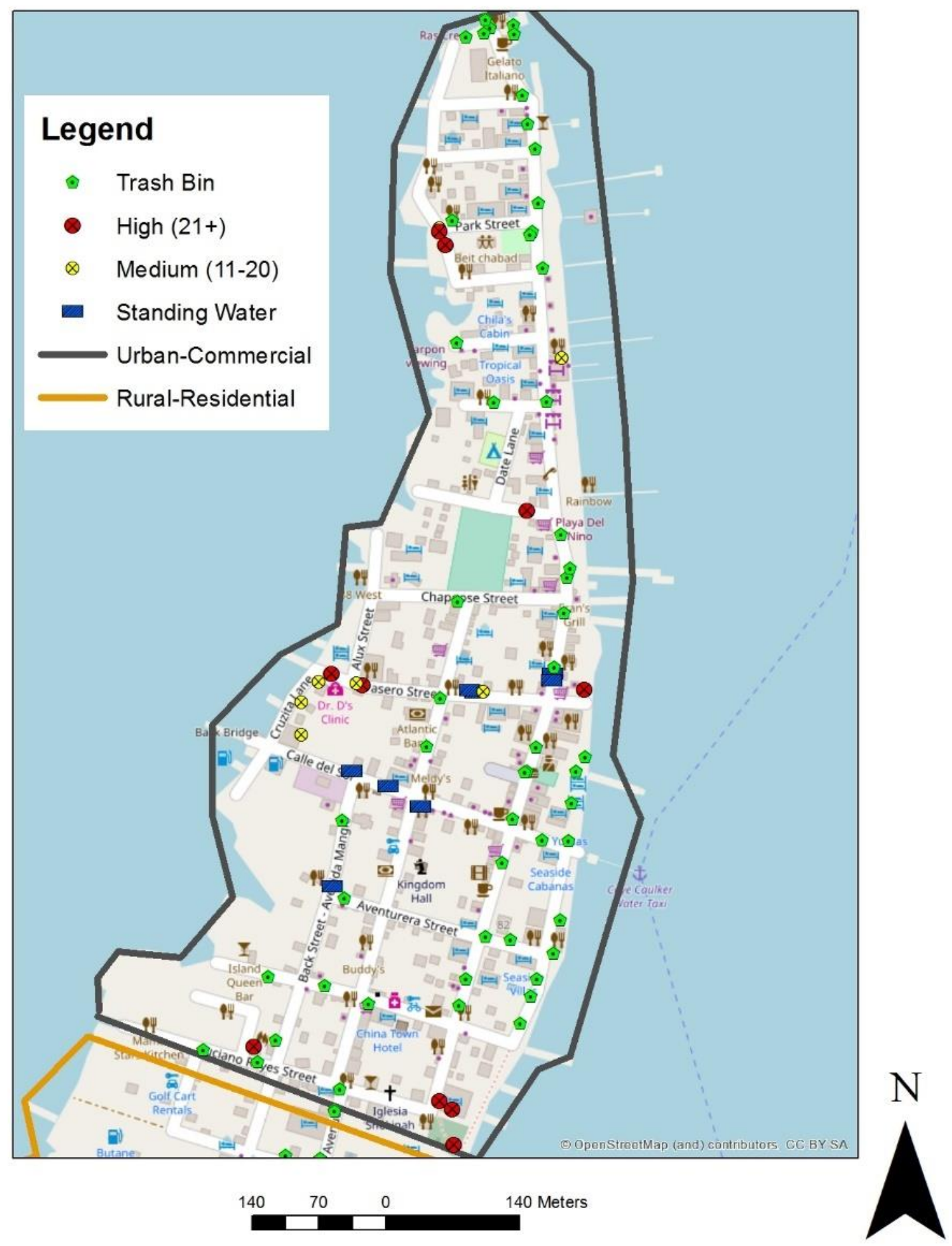

Figure 8: Distribution of trash bins, litter clustering, and standing water specific to the urban zone of Caye Caulker. 
The urban zone had 10 instances of High (21+ items), and 6 Medium (11-20 items) identified waste clustering locations. This is compared to 25 High locations and 6 Medium locations in the rural zone. This may indicate that close-proximity to available trash bins is a deterrent to littering practices, as there are very few cases of high concentrations of litter situated next to a waste receptacle. From a syndemics perspective, these maps demonstrate that social inequality and living conditions can promote health disparities and the spread of infectious diseases for the most vulnerable populations (Singer 2015, 224). With very real disparities between the allotment of municipal waste receptacles between the urban and rural region, this will further foster the capability of infectious disease agents to breed in the poorest communities of Caye Caulker. Race and ethnicity may also play a role in this discussion, as there are perceptions among islanders that the local municipality is catering to wealthy white tourists while ignoring prevalent litter in residential neighborhoods. As Manny, a waste collector I frequently spoke with, remarked when I told him I was looking for trash bins in one of the neighborhoods, "Man, you are wasting your time going that way, that's the 'black neighborhood' they don't give us trashcans there." ${ }^{23}$ This was especially interesting as community members rarely mentioned race or ethnicity to me during our many conversations.

An additional component to consider for litter dynamics are residents who do not pay for their garbage to be collected but the state expects them to carry it either by golf cart (which is generally only available to wealthy individuals or businesses) or by hand to the island's new waste collection center located in the far south-west region of the island. From here, the garbage is processed and then transported by barge to the mainland. This is a cumbersome task on-foot and I never saw residents doing this, besides by vehicle. Instead, empty lots or rural areas are

\footnotetext{
${ }^{23}$ Informal conversation with Manny (2017).
} 
often utilized as illegal dumpsites. One such location in the rural zone was originally intended to be a landfill and later converted into a community recreational field. This project was partially completed leaving a large area exposed to the open air and continual illegal dumping by residents. During participant-observation on the north side of the island I struck up a conversation with Rico, one of the rural residents. When he learned of my research interests he very eagerly decided to show me the extent of the litter problem caused by this unfinished landfill by giving me an impromptu tour. We took the twenty-minute walk to the south side of the island conversing along the way about the state of mosquitoes in Bahia, the island's most rural neighborhood. He explained that Bahia residents can not afford to fill their land with sand to stop standing water from accumulating on or near their properties, and even if someone is able to do this, their neighbor most likely will not, making it seem to him like a useless task. After arriving in Bahia, Rico approached a local resident and politely asked if we could walk behind his property, so I could see the open-air landfill. After negotiating the wooden planks that acted as a make-shift bridge we made it to our destination. As Rico explained, "Here we find the scene of the crime. They [the local government] only did half the job, they filled some of the landfill with sand but the rest is completely open. Now mosquitoes are very bad and when it rains the trash gets flooded. You can see it's also surrounded by mangroves. They filled some of the mangroves up with garbage to fill it but never finished it and moved on because of the garbage barge on the other side of Bahia." Rico put the blame on this failed project and continued littering in the hands of the local government, not residents who need to dispose of garbage. Despite this, as we walked back north Rico continued, "It's contagious, throwing garbage on the ground when you see it, it's like a virus." ${ }^{24}$ As we passed another informal dumpsite he finished

\footnotetext{
${ }^{24}$ Informal Conversations with Rico (2017)
} 
his water bottle and threw it on the ground. He did not pick it back up. In support of this ethnographic account, I found in my GIS analysis that the urban region has 54 waste bins compared to only 9 in the rural zone. To visualize this disparity, I offer one additional map where I have overlaid waste and waste receptacles over the Kernel Density map I discussed above (See Figure 9). 


\section{Business Density and Waste Management}

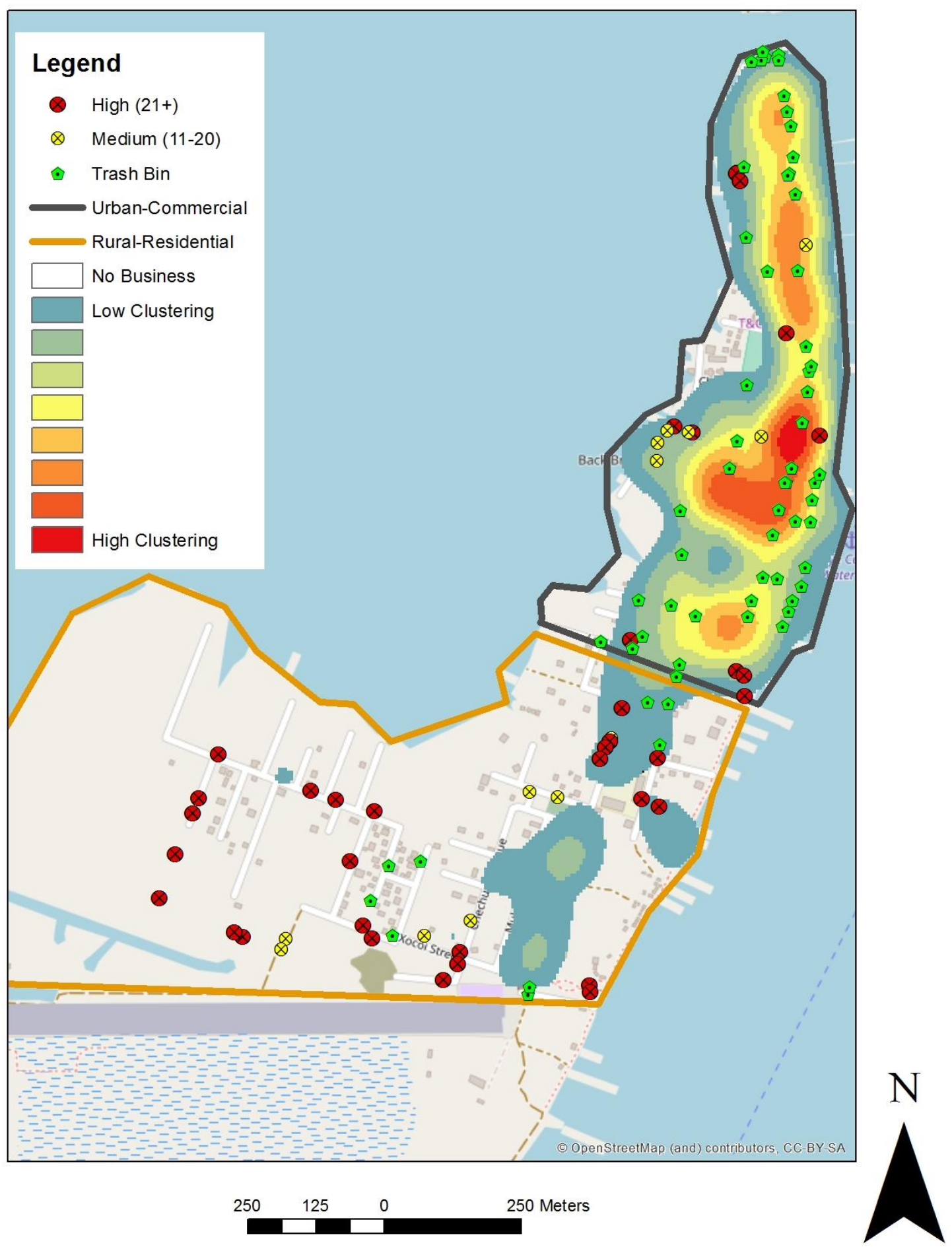

Figure 9: Business density compared to waste management in Caye Caulker. 
This map demonstrates the higher degree of clustering of waste receptacles in areas with concentrations of businesses than elsewhere on the island. Interestingly, when I had conducted preliminary fieldwork in 2016, there was much more garbage in the commercial district compared to 2017. This indicates that the new addition of these waste receptacles has a high degree of effectiveness for limiting litter, which is also evident in the relative lack of high quantities of litter in their proximity, with few exceptions.

There is another temporal component to this analysis. I noticed that after collecting waste receptacle distribution data, some receptacles were missing near the end of my fieldwork. When I inquired with a member of the village council and I was told that residents were "abusing" these free waste bins surrounding one of the elementary schools instead of paying for private garbage collectors or the fees for their own trashcan to be picked up by the municipal garbage service. A final component of these potential contributors to mosquito breeding are areas of standing water. Aside from the mangroves that were not in a close proximity to residential properties, I counted 7 instances of continuous standing water in the urban zone, and 30 in the rural region. As mosquitoes need standing water to breed, this is possibly the strongest indicator of the proximate risk of infection and supports accounts of islanders who say that mosquitoes are most concentrated in this zone. It should also be acknowledged that this map does not include private residences in the extreme south of the island. Additionally, Caye Caulker is divided into two separate "islands" by a narrow shallow-water divide colloquially known as "The Split." It was difficult for me to collect data on north island of Caye Caulker due to the quantity of insects and inaccessible terrain, but residents also live in these regions. Due to the overwhelming majority of residents living on the south island, I primarily conducted data collection in this geographic region. 
This environment of risk factors most likely contributes to Zika's endemic status on the island, and due to the pervasiveness of these factors in such a small geographic location, epidemiological surveillance is extremely difficult without tests to confirm possible cases. Additionally, healthcare providers postulate that Zika may have even reached the island as early as in 2015, based on a series of symptomatic patients with negative test results for other known mosquito-borne diseases. This contradicts official government estimates of a 2016 arrival period, further muddling understandings for health providers and policy makers concerning Zika's scope before the virus was formally identified here. The uncertain life history of Zika on the island will have implications moving forward for healthcare practitioners as they are not sure of the extent of previous or possible infections. In fact, when I was in the field less than 100 cases of Zika had been officially documented as originating in Caye Caulker, despite health practitioners expressing the likelihood that most of the population has been potentially infected based on their experiences providing care. In hindsight, the work of Kendall et al. $(1991,258)$ on dengue and urbanization is perhaps prophetic concerning Zika:

[E]merging health problems may go unrecognized and untreated because of the variable nature of the disease processes involved and the fact that the population affected may have had no previous experience with them. Awareness and concern for the problem may therefore have to be generated in affected populations, a process made difficult when a disease has a relatively insidious and invisible onset.

The invisibility of Zika in Belize might especially pertain to its current incidence level. Due to these factors influencing monitoring practices, Caye Caulker health specialists must navigate an ambiguous healthcare environment of limited infrastructure and inaccurate data collection 
procedures, constraining their ability to adequately assess and address Zika as a health problem for their patients. Interestingly members of the Village Council claim that they must wait for health inspectors from the mainland or the larger island of San Pedro to tell them when to spray, while health inspectors informed me it was up to the discretion of the Village Council to decide when is an appropriate time. This contention is important because if each party claims it is the responsibility of the other to decide when to spray, incident levels will surely rise as a result despite the relative invisibility of this disease in clinical settings.

This chapter has demonstrated the clinical uncertainty created by neoliberal structural factors, the usually asymptomatic nature of Zika, and its parallels with other vector-borne diseases when it does express symptoms. Specifically, I utilized GIS maps to spatially orient disparities in waste management infrastructure and services as well as other mosquito breeding risk factors including litter clustering and standing water. My ethnographic contributions to this discussion additionally highlight the lived-experience of Caye Caulker residents with these compounding factors, and how this creates a context of increased Zika transmission despite healthcare providers' reservations concerning the validity of Zika's declared endemic status. Community members' conceptions of Zika-related health risk and consequences will be the focus of my final findings chapter, which I supplement with additional GIS analyses that assess the extent of Zika transmission risk. 


\section{CHAPTER 6: "YOU KNOW THIS ZIKA STUFF IS JUST A MYTH, RIGHT?”: COMPETING HEALTH RISKS}

It is apparent in my analysis that islanders must navigate contradictory environments of risk perceptions, especially in relation to the perceived health consequences of fumigation interventions and Zika as a health risk. My research in the community shows that islanders see fumigation against mosquitoes as a greater risk to their health than Zika infections and believe that spraying may cause respiratory problems or lung cancer. As an example, the first day of my fieldwork also coincided with the island's vector control vehicle fumigating that day. As I curiously followed some distance behind as the truck drove around the tourist district I noticed some community members closing doors or covering their face (See Figure 10).

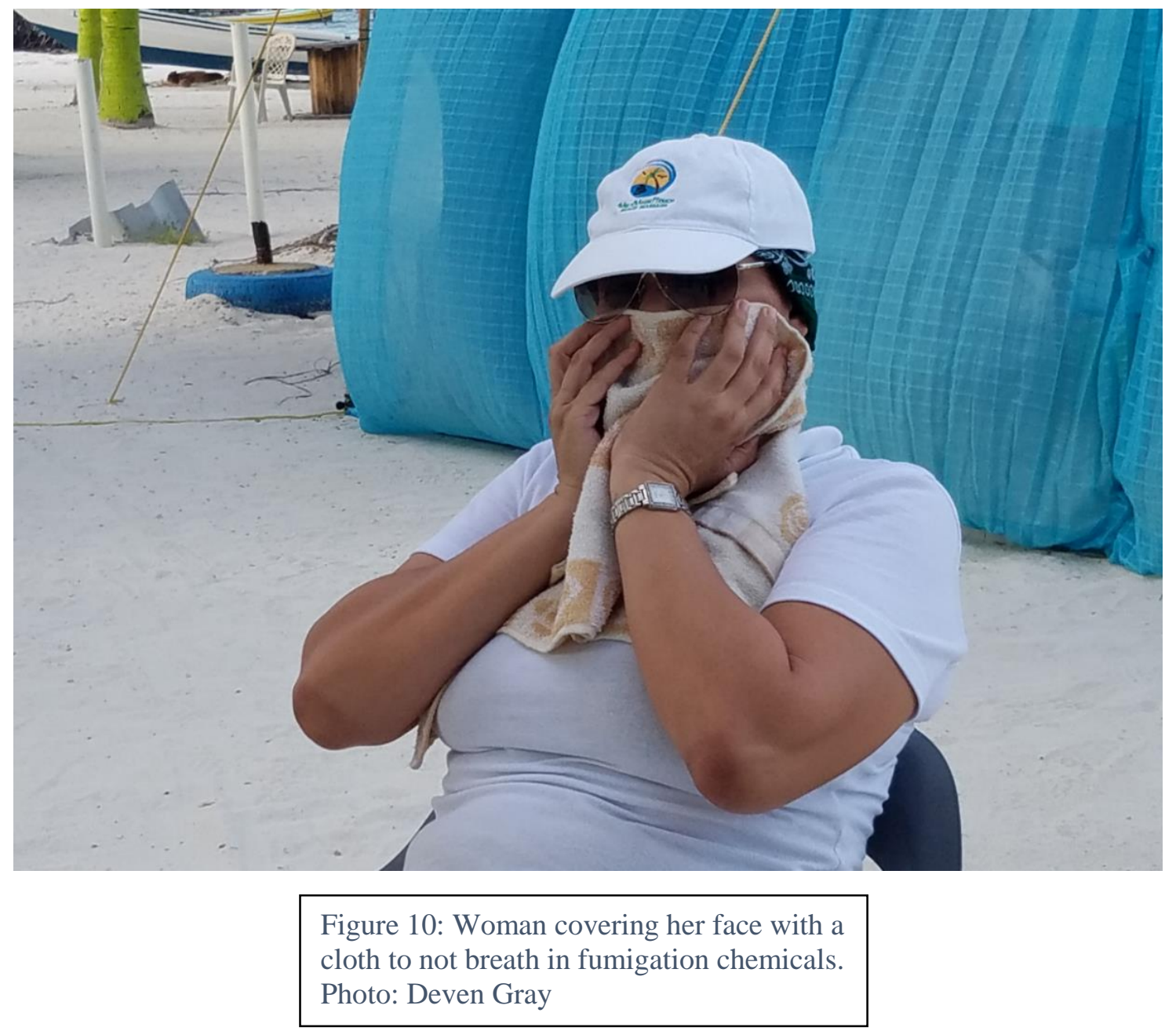


This is an interesting practice as it indicates islanders' familiarity with this intervention practice, so much so that some carry around rags to act as makeshift filtration masks. As Jerome, a local tour guide, complained to me "That stuff's cancerous, right? Man, I live on the island, I breath that shit in all the time. It can't be good for you." ${ }^{25}$ In relation to other mosquito-borne diseases, the private clinic's "dengue test" is more often chosen when individuals decide which test to take as they perceive dengue as a greater health concern than Zika. Due to the history of dengue in Belize, Caye Caulker residents are aware of the possibility for dengue hemorrhagic fever, a much more severe case of dengue infection that can be potentially fatal, which most likely influences these perceptions (Gubler, 1998). Also, despite healthcare providers perceiving Zika as a public health concern, they generally share the perception that dengue poses a greater health consequence for individuals. Community members and island officials also reported the largest amount of actively-breeding mosquito populations to be in the poorest regions of the island. Despite this pervasive knowledge, the local government tightly manages factors contributing to mosquito breeding, such as providing free garbage-collection services in the commercial district while not extending this service to poorer residential areas. As discussed, residents must pay for their garbage to be collected, which many cannot afford, so instead littering is a pervasive practice in these areas. Islanders also typically believe that Malathion fumigation spraying efforts have questionable efficacy. Likewise, this top-down fumigation efforts ignore the intimately-entangled nature of mosquito and human populations that live in constant contact (See Figures 11 and 12).

${ }^{25}$ Interview with Jerome (2017) 

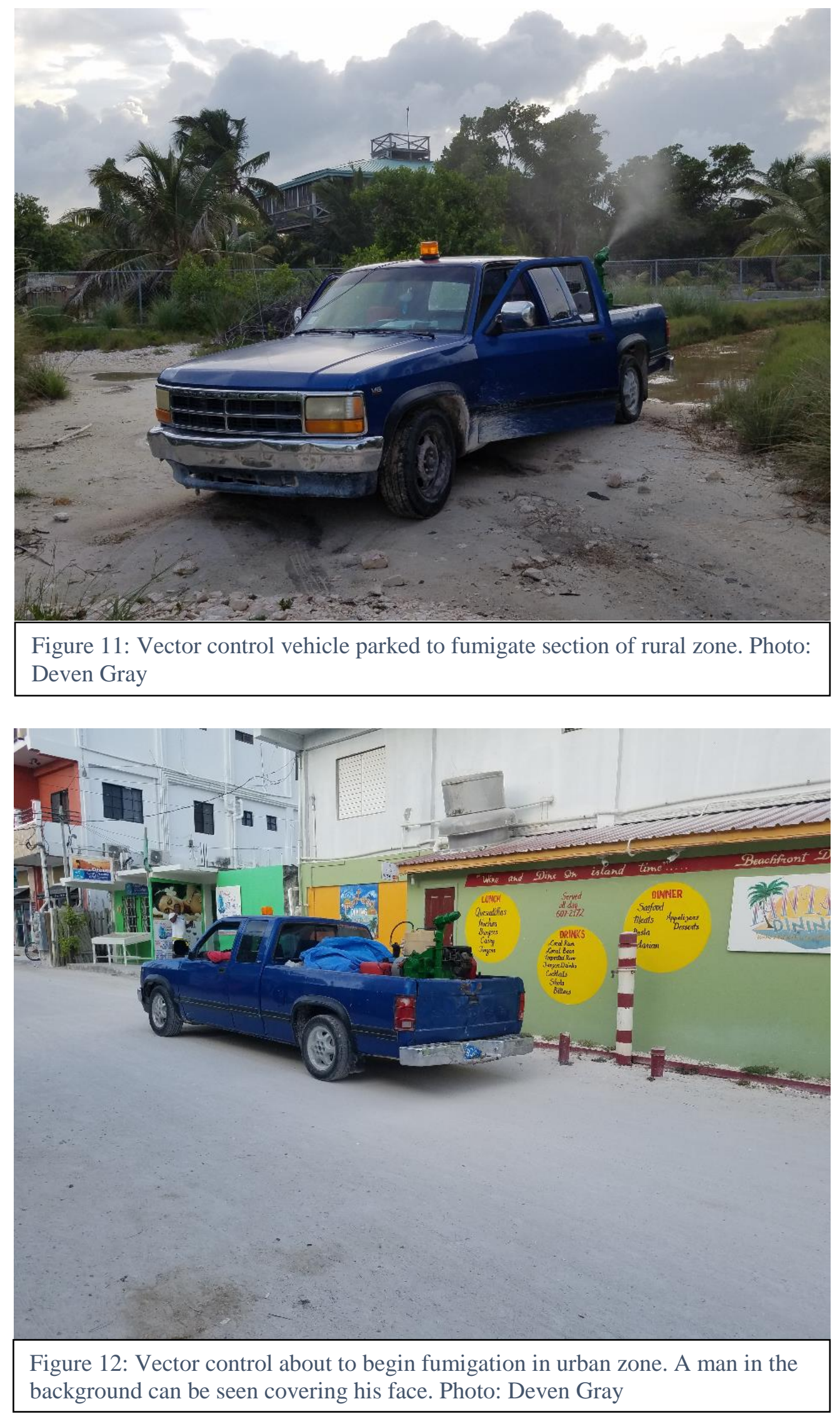
As Dr. Garcia was quick to remind me during one of our multiple interviews, "This is why it is called vector control, not eradication. ${ }^{.26}$ By this, he meant that fumigation does not address the underlying issue of mosquito breeding. Despite this, health inspectors complained to me that islanders do not listen when they urge residents to allow vector control to fumigate inside their homes. In resistance, people close their windows and doors when they hear the distinctive noise of the approaching vector-control truck. I mentioned this perspective of officials to Laura, a woman known among many islanders for selling "alternative mosquito repellants." She laughed and countered by saying, "Good, I have been telling people to close their doors because they shouldn't be breathing that stuff in. The 'health officials' are in Monsanto's pocket. You know this Zika stuff is just a myth, right? I've gotten Zika and it's just like getting a fever. It's ridiculous what they are doing in Florida and Belize.”27 This was not the first time that islanders told me about a so-called conspiracy in the context of Zika and microcephaly scares, and business owners seem largely cognizant of Zika discourses and threats in international contexts such as in Florida. Wariness of the intentions of vector control intervention as well as an almost unanimous aversion to voice recording during interviews speaks to pervasive perceptions in Caye Caulker of government corruption and surveillance, which certainly is not helped by neoliberal economic trends which limit provision of state services as such perspectives extend also to the Ministry of Health.

From a public health perspective, one also has to question the efficacy of tightly regulating factors related to mosquito breeding in one location of the island while largely ignoring another. Caye Caulker has a very small geographic footprint, so much so that it is often

\footnotetext{
${ }^{26}$ Interview with Dr. Garcia (2017).

${ }^{27}$ Interview with Laura (2017)
} 
not included in maps of the country. Additionally, mosquitoes and humans are mobile creatures, increasing the likelihood of inter-community transmission and creating a "[1]andscape of disease cocreated by active human and nonhuman elements (Nading 2014, 19). To visualize this possibility, I have created three additional maps, the first spatially orients standing water and waste, the second creates 50-meter buffer zones around these locations to visualize possible overlap for mosquito breeding, and the final presents two simulated trips from the rural neighborhood of Bahia to the closest grocery store on the island as a means to approximate risk of mosquito vector exposure (See Figures 13,14,15). 


\section{Risk Factor Zones}

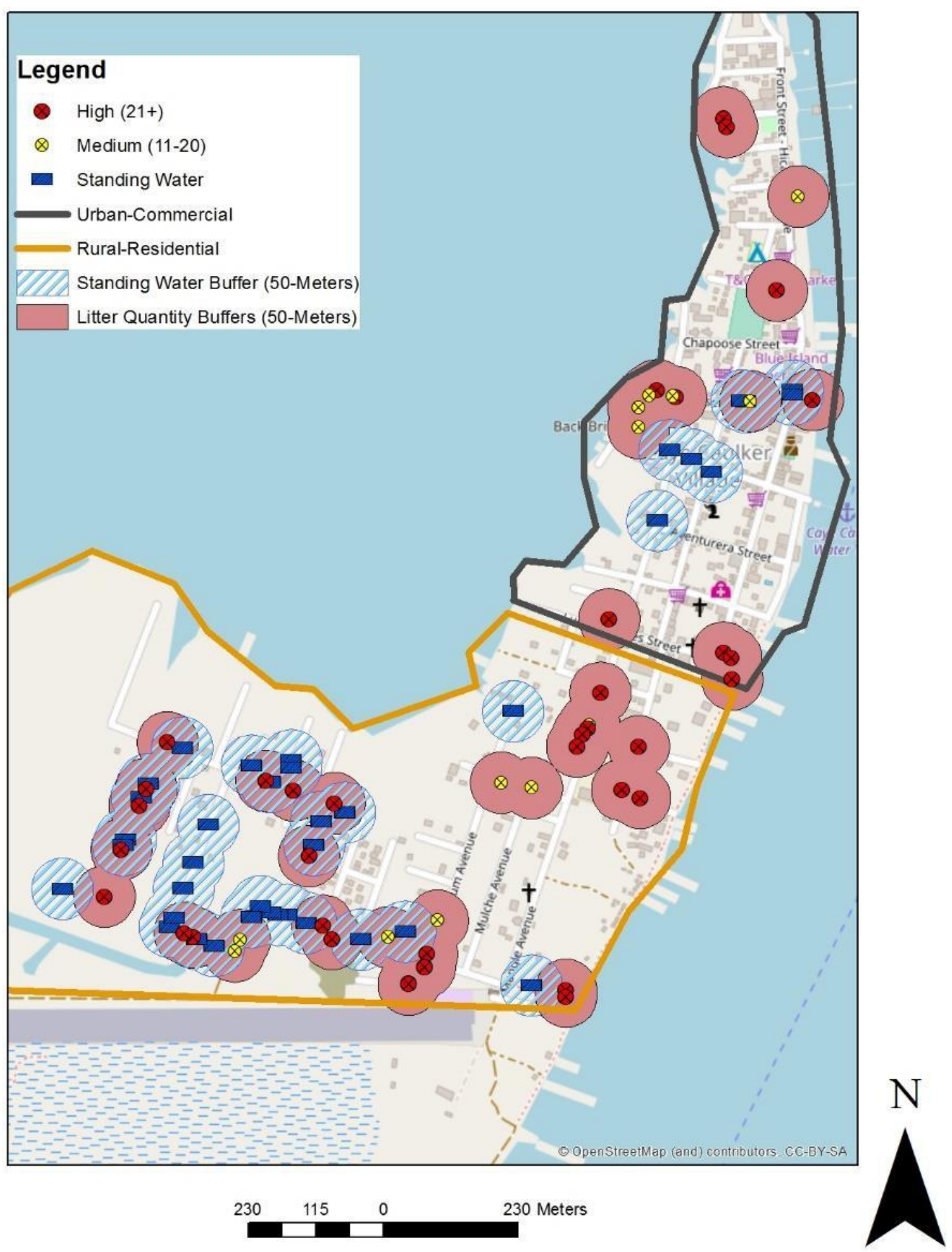

Figure 13: Risk factor analysis of litter and standing water for mosquito breeding with data points displayed overlaying 50-meter buffers. 


\section{Risk Factor Zones}

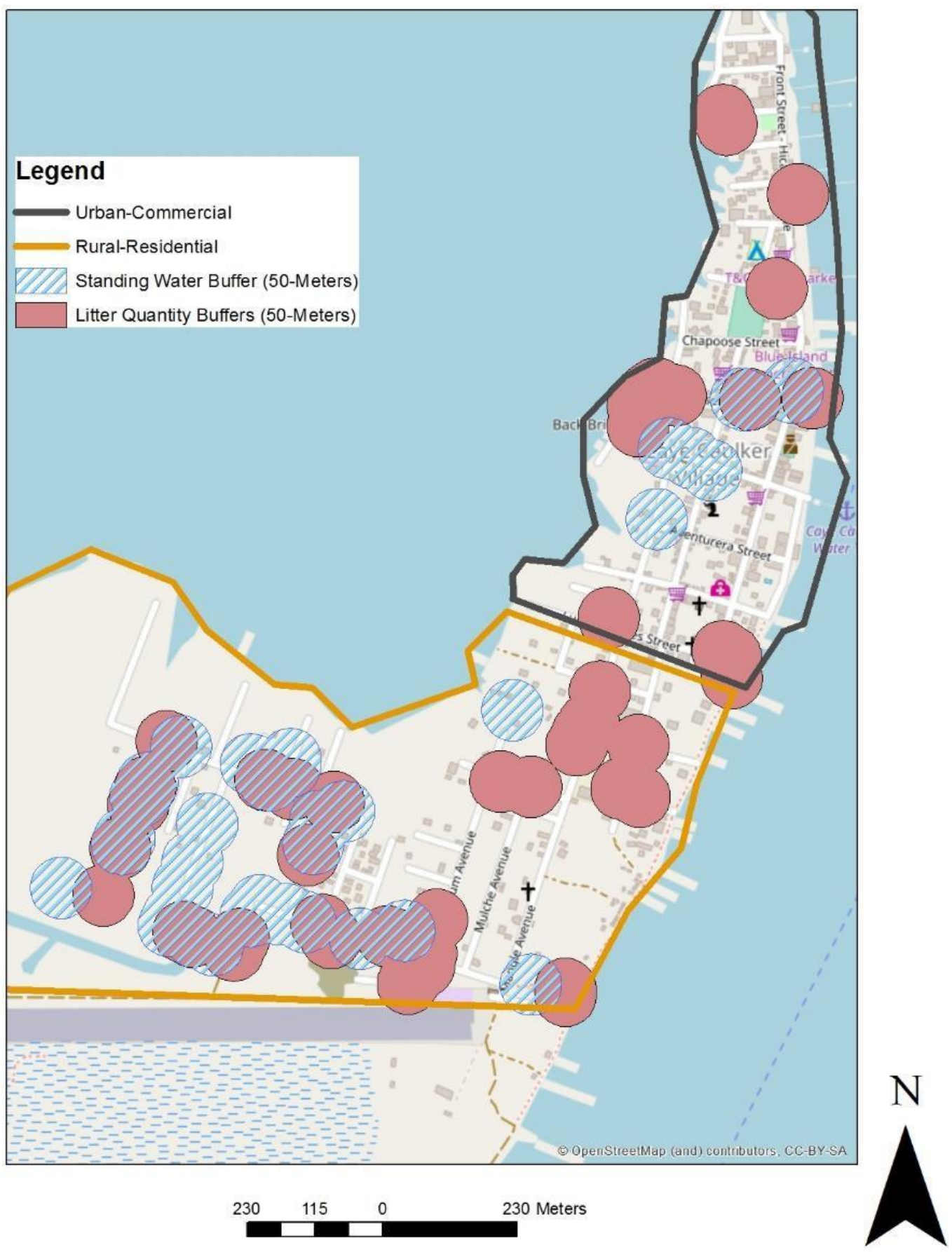

Figure 14: Risk factor analysis of litter and standing water for mosquito breeding with data points not shown. Notice overlap of standing water and litter buffer zones. 


\section{Walk to Grocery Store}

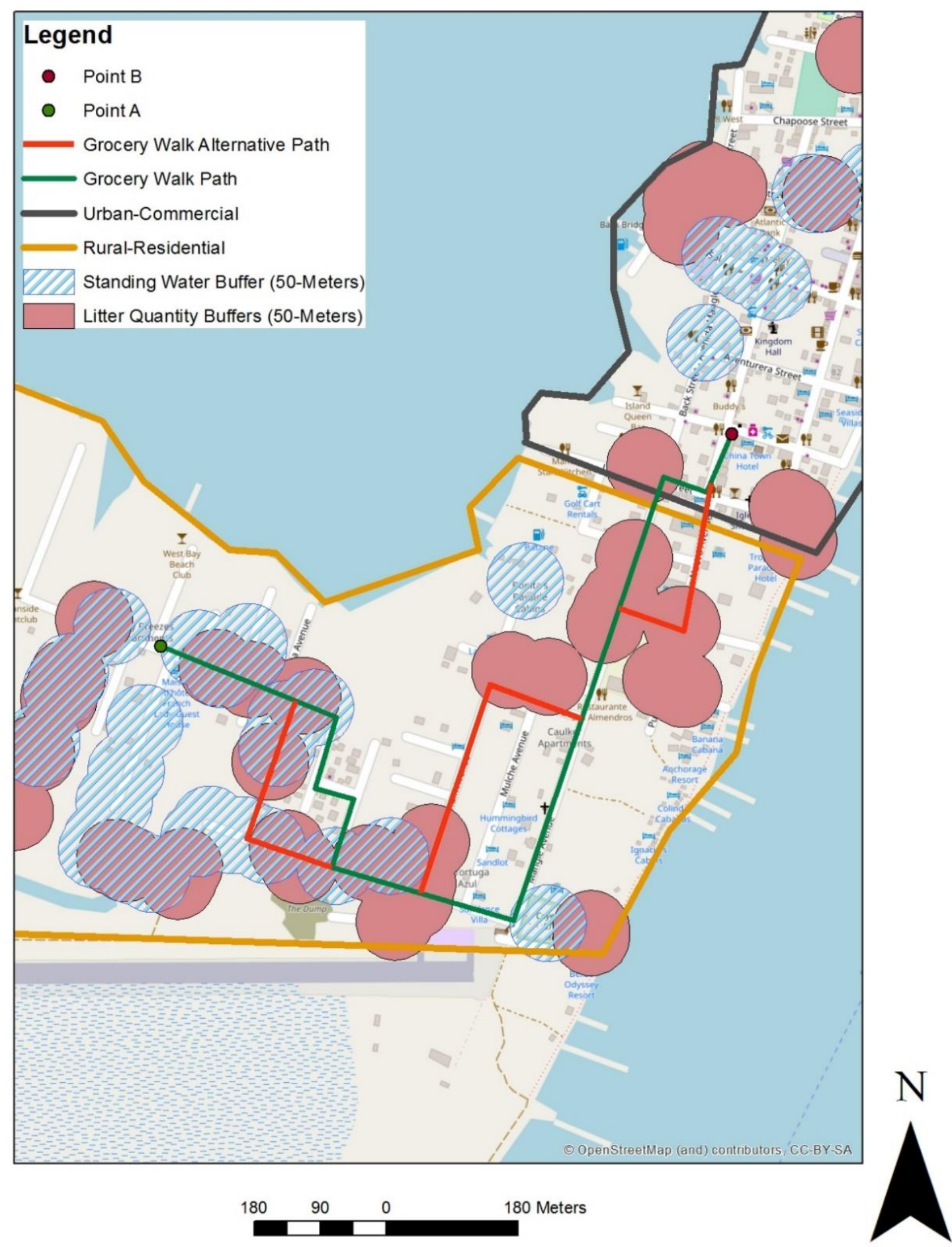

Figure 15: Two examples of commonly utilized paths for walking from the rural neighborhood of Bahia and the nearest grocery store. There are limited options for streets which I have indicated by breaking up of the red path. 
As these maps demonstrate, due to the severity of standing water and litter clustering in the rural zone, residents of Bahia are at heightened risk of infection by vectors. Mosquitoes need standing water to breed, and litter facilitates this process by providing surfaces that hold water when it rains or if they are near standing water. By my creation of 50-meter buffer zones around each of these risk factors, the possibility of overlap between each becomes apparent, leaving few "safe spaces" for residents trying to avoid mosquito bites. My additional model of two commonly-utilized walking paths between Bahia and the nearest grocery store further adds credence to the borderless nature of zoonotic diseases and physicians' worries about the majority of the island being infected. It should be noted that the location I chose for "Point A" on the grocery store walk simulation map does not correspond to a private residence to protect community members' privacy. If I had intentionally chosen one of the other streets in Bahia it would lend more weight to the validity of such a model because there are higher concentrations of overlapping sources of standing water and waste in these areas. Finally, GIS researchers have found in other global contexts that concentrations of humans in popular urban areas may in fact increase their likelihood of being possible vectors of transmission due to humans clustering in such zones (Wen et al. 2015). So, despite there being more mosquitoes in the rural region of the island, individuals may be at increased risk of infection in this supposedly buffered region despite the local municipality's efforts to limit such risk for tourists and urban residents, as there are higher concentrations of people in these zones to transmit disease via mosquito. In the context of Caye Caulker, my earlier kernel density analysis above may not only apply to clustering of businesses but also approximate vector-transmission risk. Additionally, the WHO outlines that Ae aegypti on average flies 400 meters, which is a large extent of the geography of such a small island further raising the possibility of cross-community infection (WHO 2018c). 
This has further implications for international Zika transmission despite tourists tending to stay primarily in the urban region of Caye Caulker.

This also leads to perhaps one more layer to risk assessment when weighing Zika in terms of an economic risk versus a health risk. As Caye Caulker relies almost exclusively on tourism for its income, business owners are weary of providing Zika information to tourists and think it is unfair that health organizations warn against travelling to Belize. For instance, as I searched for business owners to possibly interview about their perceptions of Zika on the island, I met Isabell, the owner of one of the modest hotels situated along the beach of Caye Caulker while she sat in her office. She argued, "The government and CDC blew this out of proportion with their travel notice [to avoid Belize], business owners are pissed off, we don't need this shit especially since they don't know what they are talking about.." ${ }^{28}$ I was initially surprised at this strong response, but her perception became clearer later on during fieldwork when I had acquired a large stack of "Noh Get Bite" pamphlets with the intention of seeing if business owners would want them and to possibly spread information on Zika before I left the field. Some business owners were grateful for the information, while others refused to accept them in fear this would scare away possible customers to their hotels or hostels. During this time, multiple individuals further complained to me that business was down compared to last year due to cancellations by families concerned about Zika. This attitude implies that those who stand to profit from Belize's lucrative tourist industry may put pressure on the state to mute potential anxieties around Zika (especially for international visitors), and simultaneously may not be inclined to cooperate with public health surveillance needed to understand the true status of Zika in Belize.

\footnotetext{
${ }^{28}$ Interview with Isabell (2017)
} 
As I have argued in this chapter, community members must navigate sometimes conflicting perceptions of Zika-related risk. Fumigation is largely seen as a greater health detriment than Zika, even to the degree that individuals are actively resisting vector control efforts on the island. Concerning other vector-borne diseases, due to the cost of private clinic testing and other structural barriers, community members assess dengue as the more logical option when choosing which test to take as it is perceived as a greater health risk, further limiting the possible scope of Zika surveillance. These issues are compounded by eco-social and syndemic factors shaping infection risk on the island, including disparities in the provision of waste management services. Despite these disparities, it is likely that Zika is being transmitted between rural and urban communities, which raises questions concerning the public health effectiveness of limiting waste management services primarily to more affluent areas. My analysis also demonstrates that business owners who depend on tourism for their livelihoods must assess the competing economic risks versus the health risks of Zika. This has further implications for not only national transmission of this disease, but also for international transmission due to Caye Caulker's position as tourism-centric location. 


\section{CHAPTER 7: CONCLUSIONS}

I have argued that despite its declared endemic status, Zika infection is not perceived as a true health concern by members of affected communities which are in most need of state health interventions. This is due to the state's contradictory approach to managing health needs. My work shows that limited state engagement in healthcare environments while at the same time restricting reproductive decision making options for women has contributed to this perception about Zika. At the level of healthcare, I found that ambiguities in clinical settings further complicate assessments of the public health consequences of Zika, and leave healthcare providers relatively powerless to treat and monitor this emerging infectious disease in Belize. My utilization of GIS maps to spatially orient structural factors contributing to Zika's possible endemic status support these findings while also demonstrating the possible scope of infection cases. Furthermore, my research data show that as a result, these structural contexts produce and shape conflicting health risk perceptions, including competing conceptions of health consequences for fumigation, other vector-borne diseases, and even the economic impacts of Zika versus risk of infection in this endemic site of transmission. By visualizing through GIS data the possibility of intracommunity disease transmission, I also call into question state's efforts to manage waste in the more affluent urban zone versus the rural regions of Caye Caulker.

Policy makers must be cognizant of how gender inequities in reproductive governance, including that of limited provision of reproductive health services, has a direct impact on perceptions of Zika-related health consequences. Likewise, the state's efforts to leave provisioning of healthcare in the hands of individuals and private for-profit businesses is short- 
sighted due to the likelihood that Zika's endemic status will spread further in the country, and potentially get worse if lack of adequate intervention efforts and environmental risk factor management continue. This research raises concerns about the compounding challenges that place an undue burden solely upon women to prevent pregnancy or pregnant women to monitor their pregnancy, especially when the Belizean state fails to provide adequate health services and infrastructure or reproductive rights to make it possible for women to control their reproduction. This context brings to light Belize's contradictory discourses urging women to prevent their pregnancy due to Zika, while not providing them the means to do so, demonstrating the state's employment of reproductive governance through moral regimes while at the same time promoting neoliberal policies that limit health services (Morgan and Roberts 2012).

Since Belize's current approach to Zika also involves managing disease vectors, this research raises further questions about state's efforts to realize this goal. As scholarship in Latin America has already shown, mosquito-borne epidemics are exacerbated by the persistence of severe inequality, including that of sanitary conditions, and political apathy to address these issues (Löwy, 2017). The Caye Caulker village council already provides free larvicide tablets for islanders that request them, but there is limited knowledge of this service and frequently supplies run out. Expanding this practice and spreading information of its efficacy would be greatly beneficial for managing mosquito populations before they reach adulthood. The way that health information is distributed is another area of concern, however, this is where critical medical anthropology is particularly useful in public health contexts. In particular, ethnographic research can critically assess structural inadequacies and local perceptions, incorporating grass-roots lived experiences and translating this knowledge into effective action (Feierman et al. 2010, 123).With Zika just being one of many emerging health problems globally (e.g. SARS, Ebola, dengue) new 
actors will be involved in this discussions at all levels of society and internationally, and the borderless nature of epidemics will necessitate medical researchers who can take an active role in potentially affected communities, especially individuals that are cognizant of how different cultural contexts shape health and wellness (Pfeiffer and Nichter 2008).

Anthropology therefore has the potential to contribute to discourses and public health interventions by actively engaging with key stakeholders including policy makers, health specialists, and community members on the ground. In the process bringing to light uneven power relations and structural inadequacies including limited participation by state institutions tasked with caring for their constituents. The Ministry of Health provides a small supply of educational "Noh Get Bite" pamphlets to the public clinic, yet many islanders were surprised when this was mentioned during fieldwork. Information campaigns could go a long way to promote concerns over the possible health consequences of this new disease for Caye Caulker, and to communicate that individuals can not solely rely on this pamphlet to assess disease symptoms. Perhaps even more crucially, the government currently only provides free waste and garbage collection in the commercial district frequented by tourists, but neglects to provide such services to the residential, poorer neighborhoods. Since mosquitoes and infections do not respect such boundaries, bringing attention to this exclusion is vital in opening public discussions about the deeper social inequities that underpin experiences with Zika in Belize. Syndemics theory can help accomplish this task, by providing a perspective that allows researchers to illuminate the often subversive and often hidden role of inadequate structural systems that can facilitate the spread of infectious agents. As I have discussed, this has been conceptualized as a form of structural violence (Farmer 2005; Singer 2015, 13) and is particularly important to consider due to the possibility of multiple diseases to cohabit an individual, further creating complications in 
clinical settings beyond Zika's generally asymptomatic nature. In order to prevent future epidemics and new cases of this disease, policy makers and public health specialists must take a more active position towards state intervention to limit the possible scope of infection risk. Such a perspective must especially be taken in countries that already have endemic diseases spread by the same possible vectors, including Belize with endemic dengue transmitted by Aedes aegypti, which is also the primary transmitter of Zika.

\section{Significance and Contributions to Scholarship}

This research contributes to multiple domains of inquiry including medical anthropology, public health, and GIS. Medical anthropology fieldwork concerned with the intersections of infectious disease and reproductive health policy are not new endeavors (Levine and Dubler 1990; Romero-Daza et al. 2013). With one locally confirmed case of microcephaly for Caye Caulker already, this disease has the potential to severely impact the health and wellness of pregnant women and future generations due to Zika's declared endemic status on the island. It will be important for anthropologists to conduct research in areas with known congenital Zika syndrome, in order to understand the lived-experience of families with this disease and to promote international as well as state intervention efforts to limit future complications, and support families dealing with challenges. A critical medical anthropology analysis can additionally highlight structural inadequacies including limited reproductive options beyond monitoring for Zika and state urgings to abstain from sex and prevent pregnancy. Also bringing attention to gender disparities in policy making positions can promote further inclusion of women in this discussion. With very few women in such positions in the Belizean parliament, promoting their voices in such health-related discourses can help bridge this gap in policy making at each level of governance. With the explosive emergence of Zika in international 
contexts, anthropologists must be cognizant of the role they may play in this constantly developing discussion.

If syndemic and reproductive governance theoretical approaches are further utilized together in response to global crises and epidemics, anthropology might be well positioned to address this health concern or those in the future. When I first proposed my thesis fieldwork I noted that there was a dearth of anthropological literature on the Zika virus. Since then, Brazilian scholars working first-hand with families affected by Zika and its aftermath in Brazil have produced burgeoning scholarship on this topic; it just appears this has been slow to reach Western eyes and publications. Debora Diniz, a professor of bioethics at the University of Brasilia has taken a crucial step forward that may be used as a model for international scholars with a recent publication translated in English on this topic (Diniz 2017). This attempt to engage scholars across borders and disciplines should be reciprocated with efforts to make available Western Zika scholarship in multiple languages to promote further and efficacious collaboration. Additionally, with the traditional emphasis of extended periods of fieldwork and the slow-pace of publication, anthropologists concerned with health must not be afraid to step into the realm of applied work and public policy engagement. Shortly after leaving the field I drafted a preliminary report for local policy makers, healthcare providers, and for possible public dissemination. Engaged anthropology such as this can provide something tangible when we leave the field, and beyond writing for our own career advancement, an effort I hope to continue.

As of writing this thesis, the 2018 summer rainy season in Belize is rapidly approaching. It is my hope that my small contribution will help local policy makers and key stakeholders in Caye Caulker make important decisions that will limit the possible risk of future Zika cases as well as structural inadequacies including uneven provision of waste and water management 
services. My work is therefore also significant for public health and policy. A critical medical anthropology concerned with how health-related policy is understood and enacted at the local level can better inform future intervention efforts with culturally-relevant and effective state engagement. With Zika being largely asymptomatic or mild, medical anthropology contributions can also better inform public health perspectives in clinical settings. As I found with conflicting perceptions of what is meant by endemic Zika, health specialists must have tools available to them to adequately assess and address Zika as a public health concern. In the case of Caye Caulker, this is not currently the case, largely due to the cost of Zika testing. The continued international spread of Zika was also on the minds of healthcare specialists I interviewed. Seeing as Zika has already mutated into at least two distinct strains of this virus, continued vector management interventions must be enacted that involves community members in this process without putting undue burden on them to do so. Providing information to individuals regardless of gender or sex will be one way to approach this challenge, to promote understanding that not only pregnant women can be affected by the transmission of this disease. Concerning reproductive policy and governance, it has been demonstrated that Zika has implications not just for congenital Zika syndrome but also maternal morbidity or incarceration due to seeking clandestine abortion services with no other available alternative. Lessening restrictive abortion policies in response to Zika may not only reduce the burden of women seeking this service, but also the strain being put on a national healthcare system already capitulating to neoliberal economic pressures.

This work is also significant in its contributions to ethnographic approaches to GIS research and fieldwork methodologies. Much has been written on the possible contributions GIS may provide to public health scholarship and epidemiology (Rushton 2003; Cromley and 
McLafferty 2011). Anthropology's active engagement with these discourses is especially important given recent attempts to acknowledge sociocultural and economic factors in disease risk in public health GIS scholarship (Rushton 2003). Along similar lines my work sought to integrate Geographic Information Systems fieldwork and analysis with ethnographic methods to study the impacts and scope of Zika in a location of endemic disease transmission. As has been demonstrated, neoliberal structural policies contribute to disease burdens in poor communities including waste and water (mis)management. Anthropology has already shown the potential for such contexts to contribute to structural violence but has been slow to geospatially orient such factors beyond acknowledging their existence. In fact, my ethnographic fieldwork combines contributions from previous GIS research in Caye Caulker (Bennett-Martin et al. 2015), and anthropology of infectious disease scholarship (Nading 2014) and advances innovative and holistic ways of triangulating data not previously possible through traditional fieldwork techniques. Spatially orienting community perceptions on multiple topics is also gaining traction in GIS scholarship (Bennett-Martin et al. 2015; Talen 2007). For instance, curious islanders sometimes asked what I was doing when walking around with a black box (my GPS receiver) and stopping periodically to collect data on my smartphone. This lead to interesting opportunities, including having islanders point on a map where they believed mosquitoes or litter to be most concentrated. Community members are much more aware of the depth of structural violence impacting their lives than foreign researchers, even if they do not conceptualize it as such. Their perspectives concerning where garbage receptacles were placed by the local government allowed for me to personally confirm this information by orientating such data spatially. Such work also has implications for Participatory Geographic Information Systems and 
Citizen Science efforts (Haklay 2013) and may serve as a new way for anthropology to engage community members as active participants in the research process.

\section{Future Research}

It is my hope that this fieldwork provides a foundation for future research in areas of anthropology of infectious diseases, endemic vector proliferation, and disease transmission, especially in Belize where I now have two field seasons of experience. I also plan to explore the continued applicability of critical medical anthropology, public health, and GIS perspectives to contribute to each of these distinct, but also interrelated, disciplines. As I have discussed, Zika is already endemic in certain regions of Belize, however it is considered an epidemic at the national-level. With dengue declared endemic throughout Belize, investigating cultural understandings of disease (Whiteford 1997) and ongoing vector control efforts will be crucial to understand the potential scope of Zika's spread at the national-level. Investigating state justifications for these declarations and how they may affect intervention efforts will be crucial to better understand the lived-experiences with disease in communities most in need of such efforts. This necessitates continued work at not just the grass-roots level, but also "studying-up" with policy makers, health specialists, and other key actors who play a direct role in such public health and governance decisions.

Additionally, with the intersections Zika research shares with infectious disease and feminist analytical approaches to reproductive governance there is merit in exploring these topics further. One potential avenue of doing so is to study ongoing efforts and experiences of HIV/AIDS in Belize, as both diseases share multiple parallels including vertical transmission from mother to fetus, sexual transmission, and prevalence in Belize (UNAIDS 2018). The World Health Organization was heavily criticized for its de-escalation of Zika as an international health 
crisis due to the potential influence this may have in reduced state and organizational intervention efforts. Anthropology is uniquely positioned to see if this has become a reality and critique such perspectives by bringing to light community experiences in areas where Zika and other diseases have been declared "Here to stay." 
APPENDIX A: IRB APPROVAL LETTER 
University of Central Florida Institutional Review Board Office of Research \& Commercialization 12201 Research Parkway, Suite 501

Central Orlando, Florida 32826-3246

Florida

Telephone: 407-823-2901 or 407-882-2276

www.research.ucf.edu/compliance/irb.html

\title{
Approval of Exempt Human Research
}

From: UCF Institutional Review Board \#1

FWA00000351, IRB00001138

To: Deven Garrett Gray

Date: April 12, 2017

Dear Rescarcher:

On 04/12/2017, the IRB approved the following activity as human participant research that is exempt from regulation:

\author{
Type of Review: Exempt Determination \\ Project Title: Managing an Epidemic: Zika Interventions and Community \\ Responses in Belize \\ Investigator: Deven Garrett Gray \\ IRB Number: SBE-17-13005 \\ Funding Agency: National Geographic Society \\ Grant Title: \\ Research ID: $\quad$ N/A
}

This determination applies only to the activities described in the IRB submission and does not apply should any changes be made. If changes are made and there are questions about whether these changes affect the exempt status of the human research, please contact the IRB. When you have completed your research. please submit a Study Closure request in iRIS so that IRB records will be accurate.

In the conduct of this research, you are responsible to follow the requirements of the Investigator Manual.

On behalf of Sophia Dziegielewski, Ph.D., L.C.S.W., UCF IRB Chair, this letter is signed by:

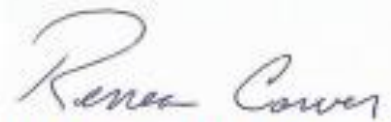

Signature applied by Renea C Carver on 04/12/2017 10:44:12 AM EDT

IRB Coordinator 
APPENDIX B: INTERVIEW GUIDE 
Thank you for agreeing to talk with me today. My name is Deven Gray, and I am an anthropologist based at the University of Central Florida. In this interview I am interested in your experiences and perspectives concerning the Zika virus in Belize. All of the information you give me will be confidential - I will not ask you for your name or any information that could identify you. You will not be compensated. This interview is voluntary and it will take 30-45 minutes to complete. Can I audio record our interview or would you prefer I did not? Would you like to start now?

Research Site:

Date: Time:

\section{Demographics:}

A.) Age (Please state):

B.) Ethnicity (Please state, as self-identified):

C.) Gender/Sex (Please state, as self-identified):

D.) Level of Education (Please state the level):

\section{Questions about Experiences and Perspectives:}

1) What have you heard about the Zika virus?

[Probes: From where or whom did you hear this information? Have you been given any pamphlets or other educational material? What is your perspective on Zika? Where do you think Zika comes from?

2) If you thought you might have Zika, would you go to a health clinic?

[Probes: Can you explain? If a clinic thought you had Zika, what do you think they would do or say? Is it worth the effort to go?]

3) Do you think Zika is a problem in your community?

[Probes: Why/why not?, Is it a problem for other people in your community? What about Belize as a whole?]

4) Do you know if the government or other organizations are trying to manage mosquitoes or Zika in your community?

[Probes: If so: How are they doing this? Is it effective, and can you explain? If not: Do you think they should? Why haven't they?, and are mosquitoes a problem?]

5) Are you or people you know doing anything to prevent mosquitoes from laying larvae or biting you?

[Probes: If so, what? Is this worth it?, If not, why aren't you/they doing so?, Where do you think mosquitoes come from? Can you explain?] 


\section{REFERENCES}

Ali, Moazzam, Kelsey Miller, and Rodolfo Federico Gómez Ponce de Leon. 2017. "Family planning and Zika virus: need for renewed and cohesive efforts to ensure availability of intrauterine contraception in Latin America and the Caribbean." European Journal of Contraception \& Reproductive Health Care. 22, no. 2: 102-106.

Alley, Christopher, and Johannes Sommerfeld. 2014. "Infectious Disease in Times of Social and Ecological Change.” Medical Anthropology. 33: 85-91

Andaya, Elise, and Joanna Mishtal. 2016. "The Erosion of Rights to Abortion Care in the United States: A Call for Renewed Anthropological Engagement with the Politics of Abortion." Medical Anthropology Quarterly. 31, no. 1: 40-59.

Arunachalam, N, S Tana, F. Espino, P Kittayapong, W. Abeyewickreme, K.T. Wai, BK. Tyagi, A. Kroeger, J. Sommerfeld, and M. Petzold. 2010. "Eco-bio-social determinants of dengue vector breeding: a multicountry study in urban and periurban Asia." Bulletin Of The World Health Organization 88, no. 3: 173-184

Bennett-Martin, Paulita, Visaggi, Christy, Hawthorne, Timothy. 2015. "Mapping marine debris across coastal communities in Belize: developing a baseline for understanding the distribution of litter on beaches using geographic information systems. Environmental Monitoroing and Assessment. 188, no. 10: 1-16.

Bernard, H. R. 2006. Research Methods in Anthropology: Qualitative and Quantitative Approaches. Fourth Edition. Lanham, MD: AltaMira Press.

Bolstad, Paul. GIS Fundamentals: A First Text on Geographic Information Systems. White Bear Lake, MN: Eider Press, 2012.

Brown, Peter, George Armelagos, and Kenneth Maes. 2012. "Humans in a World of Microbes: | The Anthropology of Infectious Disease." In Companion to Medical Anthropology, edited by Merrill Singer and Pamela Erickson, 253-270. Malden, MA: Wiley

CDC - Centers for Disease Control and Prevention. 2017a. "Patient Counseling." Centers for Disease Control and Prevention. Accessed November 1, 2017. https://www.cdc.gov/zika/hc-providers/reproductive-age/patient-counseling.html

CDC - Centers for Disease Control and Prevention. 2017b. "Zika Virus in Belize." Centers for Disease Control and Prevention. Accessed November 18, 2017. https://wwwnc.cdc.gov/travel/notices/alert/zika-virus-belize\#partner

CDC - Centers for Disease Control and Prevention. 2018. "Symptoms." Centers for Disease Control and Prevention. Accessed March 4, 2018. 
https://www.cdc.gov/zika/about/overview.html

Center for Reproductive Rights. 2016. "Centering Human Rights in the Response to Zika." Center for Reproductive Rights. Accessed September 25, 2017.

http://www.reproductiverights.org/document/centering-human-rights-in-the-response-to-zika

Cromley, Ellen, and Sara McLafferty. 2011. GIS and Public Health. The Guilford Press. New York, London.

DeWalt, Kathleen M., DeWalt, Billie R. 2011. Participant Observation: A Guide for Fieldworkers. 2nd ed. Lanham, MD: Rowman \& Littlefield.

Diniz, Debora. 2017. Zika: From the Brazilian Backlands to Global Threat. Zed Books Ltd.

El-Zeiny, Ahmed, El-Hefni, Asmaa, and Mohamed Sowilem. 2016. "Geospatial techniques for environmental modeling of mosquito breeding habitats at Suez Canal Zone, Egypt." The Egyptian Journal of Remote Sensing and Space Sciences.

Eisenberg, Merrill. 2011 Medical Anthropology and Public Policy, in A Companion to Medical Anthropology, ed. Merrill Singer and Pamela Erickson. 97-116. Malden, MA: Wiley

ECDC - European Centre for Disease Prevention and Control. 2018. "Aedes aegypti - Factsheet for experts." European Centre for Disease Prevention and Control. Accessed March 23, 2018. https://ecdc.europa.eu/en/disease-vectors/facts/mosquito-factsheets/aedes-aegypti

Esri 2018a. "Optimized Hot Spot Analysis.” Esri. Accessed March 8, 2018. http://desktop.arcgis.com/en/arcmap/10.3/tools/spatial-statistics-toolbox/optimized-hot-spotanalysis.htm. Accessed April 2, 2017.

Esri 2018b. "How Kernel Density Analysis Works.” Esri. Accessed March 10, 2018. http://pro.arcgis.com/en/pro-app/tool-reference/spatial-analyst/how-kernel-density-works.htm

Farmer, Paul 2005. Pathologies of Power: Health, Human Rights, and the New War on the Poor. University of California Press.

Farmer, Paul. 2014. "Diary." London Review of Books 36, no. 20: 38-39

Feierman, S., Kleinman, A., Stewart, K., Farmer, P. and V. Das. 2010. “Anthropology, Knowledge-Flows and Global-Health." Global Public Health, 5(2), 122-128.

Fetterman, David M. Ethnography: Step-by-step. 3rd ed. Vol. 17. Los Angeles: SAGE, 2010

Government of Belize and Caribbean Development Bank. 2010. "Country Poverty Assessment." Halcrow Group Limited. Accessed January 25, 2018.

http://www.caribank.org/uploads/2012/12/Belize-2009-Report-Vol1.pdf

Gravlee, Clarance, C. 2011. Research Design and Methods in Medical Anthropology, In A 
Companion to Medical Anthropology, edited by Merrill Singer and Pamela Erickson, 253-270. Malden, MA: Wiley

Gubler, Duane. 1998. "Dengue and Dengue Hemorrhagic fever." Clinical Microbiology Review. 11, no. 3: 480-496.

Gutmann, Matthew. 2011. Planning Men out of Family Planning: A Case Study from Mexico, in Reproduction, globalization, and the state: new theoretical and ethnographic perspectives, ed. Browner, C. H., and Carolyn F. Sargent. Durham, NC : Duke University Press.

Haklay, Muki. 2013. Citizen Science and Volunteered Geographic Information: Overview and Typology of Participation. ed. Sui D. and Goodchild M. 105-122. In Crowdsourcing Geographic Knowledge.

Hammersley, Martyn, and Paul Atkinson. 2007. Ethnography-Principles in practice. 3rd ed. Routledge Taylor and Francis Group, London and New York

Harvey, David. 2007. A Brief History of Neoliberalism. Oxford: OUP Oxford.

Hoffman, David M. (2006) Swimming Through Fieldwork: Constructing Trust in the Mexican Caribbean. In Dispatches From the Field: Neophyte Ethnographers in a Changing World. Andrew Gardner and David M. Hoffman, eds. Pp. 15-32. Long Grove: Waveland Press

Human Rights Watch. 2017. "Neglected and Unprotected: The Impact of the Zika Outbreak on Women and Girls in Northeastern Brazil. Accessed January 28, 2018.

https://www.hrw.org/report/2017/07/12/neglected-and-unprotected/impact-zika-outbreakwomen-and-girls-northeastern-brazil

Humes, Aaron. 2016a. "Belize still free of Zika; Ministry of Health holds sensitization meeting." Breaking Belize News. February 9, 2016. Accessed February 3, 2016.

https://www.breakingbelizenews.com/2016/02/09/ministry-health-belize-continues-free-zikavirus/

Humes, Aaron. 2016b. "U.S. couple caught Zika in Belize." Breaking Belize News. April 8, 2016. Accessed February 3, 2016. https://www.breakingbelizenews.com/2016/02/09/ministryhealth-belize-continues-free-zika-virus/

Inhorn, Marcia. 2006. "Defining Women's Health: A Dozen Messages from More than 150 Ethnographies.” Medical Anthropology Quarterly, 20, no. 3: 345-378.

Jones, Patrick. 2003. "Illegal abortions: rising threat to Belizean women.” News 5 Belize Accessed: November 27, 2017. http://edition.channel5belize.com/archives/15069

Kendall, Carl, Patricia Hudelson, Elli Leontsini, Peter Winch, Linda Lloyd, and Fernando Cruz. 1991. "Urbanization, Dengue, and the Health Transition: Anthropological Contributions to International Health." Medical Anthropology Quarterly, New Series, 5, no. 3: 257-68. 
Lara, D., Abuabara K., Grossman D.. and C. Diaz-Olavarrieta. 2006. "Pharmacy provision of medical abortifacients in a Latin American city." Contraception. 74, no. 5: 394-399.

Levine, Carol, and Nancy Neveloff Dubler. 1990. "Uncertain Risks and Bitter Realities: The Reproductive Choices of HIV-Infected Women.” The Milbank Quarterly, 68, no. 3: 321-351

Li, Rui, Katharine B. Simmons, Jeanne Bertolli, Brenda Rivera-Garcia, Shanna Cox, Lisa Romero, and Scott D. Grosse, et al. 2017. "Cost-effectiveness of increasing access to contraception during the Zika virus outbreak, Puerto Rico, 2016." Emerging Infectious Diseases 1: 74-82.

Lindauer, David. 2014. "Labor Market Performance in Belize.” Inter-American Development Bank. https://publications.iadb.org/bitstream/handle/11319/6455/TN\%20Labor\%20Market\%20 Performance\%20in\%20Belize.pdf?sequence=1

Löwy, Ilana. 2017. "Leaking Containers: Success and Failure in Controlling the Mosquito Aedes aegypti in Brazil." American Journal of Public Health 107, no. 4: 517-524

McNeil, D. G. Jr. 2016. “Zika is No Longer a Global Emergency, W.H.O. Says.” New York Times. November 18, 2016. Accessed January 28, 2018.

https://www.nytimes.com/2016/11/19/health/who-ends-zika-global-health-emergency.html

Ministry of Health. 2016. "Policy, Planning and Project Management: The Newsletter." Ministry of Health. Accessed September 27, 2017. http://health.gov.bz/www/attachments/article/878/PAPU\%20Newsletter\%202016_Volume $\% 202, \% 20$ Issue\%201.pdf

Morgan, Lynn M., and Elizabeth F.S. Roberts. 2012. "Reproductive governance in Latin America." Anthropology \& Medicine 19(2), 241-254.

Nading, Alex M. 2014. Mosquito Trails: Ecology, Health, and the Politics of Entanglement. Berkeley: University of California Press.

National Women's Commission. 2012. “Toward Equality of Opportunity for Equality of Results: A Situation Analysis of Gender and Politics in Belize." Accessed November 19, 2017. http://www.bz.undp.org/content/belize/en/home/library/womensempowerment/publication_111.htmlOpenStreetMap.

OpenStreetMap. 2016. “Open Street Map.” Accessed November 29, 2016. http://www.openstreetmap.org/.

PAHO - Pan American Health Organization. 2016. "Zika Ethics Consultation: Ethics Guidance on Key Issues." Pan American Health Organization. Accessed September 25, 2017. http://iris.paho.org/xmlui/handle/123456789/28425 
PAHO - Pan American Health Organization. 2017. "Zika - Epidemiological Report Belize." Pan American Health Organization. Accessed November 8, 2017.

http://www.paho.org/hq/index.php?option=com_docman\&task=doc_view\&gid=35105\&

Itemid=270\&lang=en

PAHO - Pan American Health Organization. 2018. "Belize.” Pan American Health

Organization. Accessed February 1, 2018.

Pfeiffer, James, and Mark Nichter. 2008. "What Can Critical Medical Anthropology Contribute to Global Health?: A Health Systems Perspective." Medical Anthropology Quarterly. 22(4), 410-415.

Pope, Kevin, Masuoka, Penny, Rejmankova, Eliska, Grieco, John, Johnson Sarah, and Donald Roberts. 2005. "Mosquito Habitats, Land Use, and Malaria Risk in Belize from Satellite Imagery." Ecological Applications. 15, no. 4: 1223-1232

Quammen, David. 2014. Ebola: the natural and human history of a deadly virus. New York, NY: W. Norton \& Company.

Richardson, R.B. 2007. Economic Development in Belize: Two Steps Forward, Two Steps Back. In Taking Stock: Belize at 25 years of Independence. ed. B. Balboni and J. Palacio. Benque Viejo del Carmen, Belize: Cubola Books.

Rodriguez-Morales, Alfonso J., Carlos Julian García-Loaiza, Maria Leonor Galindo-Marquez, Juan Alejandro Sabogal-Roman, Santiago Marin-Loaiza, Carlos O. Lozada-Riascos, and Fredi A. Diaz-Quijano. 2016. "Zika infection GIS-based mapping suggest high transmission activity in the border area of La Guajira, Colombia, a northeastern coast Caribbean department, 20152016: Implications for public health, migration and travel." Travel Medicine \& Infectious Disease 14, no. 3: 286-288.

Romero-Daza, N., J. Baldwin, C. Lescano, H.J. Williamson, D.L. Tilley, I. Chan, M.Tewell, and W.R. Palacios. 2013. Syndemic Theory as a Model for Training and Mentorship to Address HIV/AIDS Among Latinos in the U.S. Annals of Anthropological Practice 35, no. 1: 232-256.

Rushton, Gerard. 2003. "Public Health, GIS, and Spatial Analytic Tools." Annual Review of Public Health. 24: 43-56.

San Pedro Sun. 2016. "Zika Officially Classified as Endemic in Caye Caulker.” The San Pedro Sun. Accessed: November 27, 2017. https://www.sanpedrosun.com/health/2016/09/09/zikaofficially-classified-as-endemic-in-caye-caulker/

Scheper-Hughes, Nancy, and Margaret M. Lock. 1987. "The Mindful Body: A Prolegomenon to Future Work in Medical Anthropology." Medical Anthropology Quarterly 1, no. 1: 6-41.

Singer, Merrill. 2010. Ecosyndemics: Global Warming and the Coming Plagues of the $21^{\text {st }}$ Century. In Plagues and Epidemics: Infected Spaces Past and Present, ed. by Alan Swedlund and Ann Herring, 21-37. London: Berg. 
Singer, Merrill. 2015. The Anthropology of Infectious Disease. Walnut Creek, CA: Left Coast Press.

Singer, Merrill. 2017. "The spread of Zika and the potential for global arbovirus syndemics." Global Public Health 12(1), 1-18.

Smith, Lauren. 2012. "The Cultural Conceptions of Dengue Fever in the Cayo District of Belize." Human Organization 71, no. 1: 65-75.

Sobo, Elisa J. 2009. "Medical Travel: What it Means, Why it Matters." Medical Anthropology. 28, no. 4: 326-335.

Statistical Institute of Belize. 2010. "Belize Population and House Census: 2010 Country Report.” Belmopan, Belize. Pp. 1-176. http://sib.org.bz/wp-content/uploads/2017/05/Census_Report_2010.pdf

Statistical Institute of Belize and UNICEF. 2016. "Multiple Indicator Cluster Survey 2015: Key Findings." Belmopan, Belize. Pp. 1-26. https://www.unicef.org/belize/MICS_Key_Findings_Report_2015_Final_Aug19(1).pdf

Talen, Emily. 2007. "Bottom-up GIS: A New Tool for Individual and Group Expression in Participatory Planning." Journal of the American Planning Association. 3: 279-294.

UCSF Global Health Group. 2015. "Country Briefing: Eliminating malaria in Belize.” UCSF. Accessed January 25, 2018.

https://globalhealthsciences.ucsf.edu/sites/globalhealthsciences.ucsf.edu/files/pub/belize2015updated.pdf

UNAIDS. 2018. “Country: Belize.” United Nations. Accessed March 12, 2018. http://www.unaids.org/en/regionscountries/countries/belize

United Nations. 2017a. "Social and economic costs of Zika can reach up to US\$ 18 billion in Latin America and the Carribean." United Nations. Accessed February 1, 2018. http://www.undp.org/content/undp/en/home/news-centre/news/2017/04/06/social-andeconomic-costs-of-zika-can-reach-up-to-us-18-billion-in-latin-america-and-the-caribbean.html

United Nations. 2017b. "Abortion Policies a Global Review." Accessed November 18, 2017. http://www.un.org/esa/population/publications/abortion/profiles.htm

Uzwiak, Beth, A., Siobhan Curran. 2015. "Gendering the Burden of Care: Health Reform and the Paradox of Community Participation in Western Belize." Medical Anthropology Quarterly. 30, no. 1: 100-121.

Wen, Tzai-Hung, Lin, Min-Hau, Teng, Hwa-Jen, and Chang, Niann-Tai. 2015. "Incorporating the human-Aedes mosquito interactions into measuring the spatial risk of urban dengue fever." 
Applied Geography. 62: 256-266.

Whiteford, Linda. 1997. "The Ethnoecology of Dengue Fever." Medical Anthropology Quarterly. 11, no. 2: 202-223.

WHO - World Health Organization. 2016. "WHO statement on the first meeting of the International Health Regulations (2005) (IHR 2005) Emergency Committee on Zika virus and observed increase in neurological disorders and neonatal malformations." World Health Organization. Accessed February 1, 2018.

http://www.who.int/mediacentre/news/statements/2016/1st-emergency-committee-zika/en/

WHO - World Health Organization. 2018a. "The history of the Zika virus." World Health Organization. Accessed February 1, 2018. http://www.who.int/emergencies/zikavirus/timeline/en/

WHO - World Health Organization. 2018b. "Key Country Indicators: Belize key indicators." World Health Organization. Accessed February 1, 2018.

http://apps.who.int/gho/data/node.cco.ki-BLZ?lang=en

WHO - World Health Organization. 2018c. "Dengue control: The mosquito." World Health Organization. Accessed March 23, 2018. http://www.who.int/denguecontrol/mosquito/en/

Women on Waves. "Belize: Abortion Law." Women on Waves. Accessed November 18, 2017. https://www.womenonwaves.org/en/page/5108/belize--abortion-law.

World Bank. 2017. "GDP per capita (current US\$).” World Bank. Accessed February 1, 2018. https://data.worldbank.org/indicator/NY.GDP.PCAP.CD 